\title{
Title: Organ transformation by environmental disruption of epigenetic memory
}

Authors: Orli Snir ${ }^{1, \dagger}$, Michael Elgart ${ }^{1, \dagger}$, Filippo Ciabrelli ${ }^{2}$, Shlomi Dagan ${ }^{1}$, Iris Aviezer ${ }^{1}$, Elizabeth Stoops ${ }^{1}$, Giacomo Cavalli ${ }^{2,}$ and Yoav Soen ${ }^{1, *}$.

Affiliations:

${ }^{1}$ Department of Biomolecular Sciences, Weizmann Institute of Science, 234 Herzl Street, 7610001, Israel.

${ }^{2}$ Institute of Human Genetics, UMR9002 CNRS, University of Montpellier, 141 Rue de la Cardonille, 34396 Montpellier Cedex 5, France.

* Correspondence: yoavs@weizmann.ac.il (Y.S)

$\uparrow$ Co-first authors

\section{Abstract}

Unlike recent progress in cellular reprogramming, the mechanisms and requirements for misspecification of entire organs are largely unknown. A canonic model for organ "reprogramming" was provided by the induction of haltere-to-wing transformations in response to early exposure of fly embryos to ether. Using this model, we identify a mechanistic chain of events explaining why and how stage-specific exposure leads to organ transformation at a later stage. We show that ether interferes with protein integrity and compromises Trithorax-mediated establishment of H3K4 tri-methylations. The altered pattern of H3K4me3 pre-disposes earlymethylated Ubx targets and wing genes for later up-regulation in the larval haltere disc, hence the wing-like outcome. Consistent with protein destabilization by ether, this transformation is enhanced by reduced function of $\mathrm{Hsp} 90$ and emerges spontaneously by joint deficiency in $H s p 90$ and Trithorax. The morphogenetic impact of chaperone response at the onset of epigenetic patterning may comprise a general scheme for organ reprogramming by environmental cues.

\section{Main Text}

Cell identities and patterns of expression in flies are established during embryonic development and are maintained by epigenetic means, particularly by the Polycomb and Trithorax systems ${ }^{1,2}$. Early embryonic exposure to environmental stimuli (e.g. ether vapor and heat) can alter these patterns and induce homeotic transformations, such as haltere-to-wing (bithorax) phenocopies ${ }^{3-8}$. The induced bithorax phenocopies can be further stabilized (assimilated) by repeated exposures over several generations ${ }^{4,9,10}$. Consistent with the similarity to the phenotypes of Ultrabithorax mutations, the penetrance of the induced phenocopy is enhanced by loss-of-function mutations in $U b x$, and its upstream regulators, $\operatorname{tr} x{ }^{10,11}$. However, the molecular mechanisms that mediate the induction are unknown and key general questions were not addressed. In particular, it is not clear: (i) How brief exposure during early embryogenesis leads to stable morphogenetic change in the adult? (ii) what determines the identity of the transformation (e.g. form haltere to wing)? (iii) why similar transformations are caused by very different inducers (e.g. ether and heat)? and (iv) why the transformation requires exposure that is restricted to a narrow time window (earlier and later exposures result in complete lethality and no effect, respectively)?

By analyzing the effects of exposure to ether, we provide evidence for a mechanistic chain of events, connecting early exposure to ether with induction of haltere-to-wing transformations. We show that ether vapor disrupts native folding of proteins in the embryo and severely compromises trx function and $\mathrm{H} 3 \mathrm{~K} 4 \mathrm{me} 3$ deposition at a critical stage of development. This interferes with 
epigenetic patterns and predisposes wing development genes for later up-regulation in the larval haltere disc. In line with a functional involvement of protein stress and reduced $\mathrm{H} 3 \mathrm{~K} 4 \mathrm{me} 3$, we show that genetic loss of function or chemical inhibition of the Hsp90 chaperone enhances the bithorax induction and that a combined reduction in $H s p 90$ and trx dosage can generate a bithorax phenotype without exposure to ether. Our findings directly link increased demand for Hsp90 function with compromised patterns of epigenetic marks and long lasting effects on mis-expression of key developmental regulators. This scenario is also consistent with all the previous evidence regarding environmental induction of bithorax phenocopies, including by exposure to heat at this critical stage in development.

\section{Results}

\section{Induction of a bithorax phenocopy with marginal effect on survival}

Previous work on the bithorax phenocopy has been performed following several different protocols $7,9,11,12$. Since the mechanisms of induction might be confounded by co-occurring selection of existing variations, we evaluated the exposure protocols with respect to their impact on survival and phenotypic effect. In particular, we compared the outcomes of exposure, with and without prior egg dechorionation (Fig. 1A). In each case, we scored the number and fraction (penetrance) of individuals (adult flies and uneclosed pupae) exhibiting a bithorax phenocopy. The latter was defined by assessing pupae and adults for morphological abnormalities in the $3^{\text {rd }}$ thoracic segment resembling the $2^{\text {rd }}$ thoracic segment $6,7,12,13$ (Fig. 1B). Exposure of intact $(y w)$ embryos to ether induced bithorax phenocopy in $\sim 9 \%$ of the individuals (Fig. 1C) and reduced the survival (number of larvae hatching) to $80 \%$ (Fig. 1D). The penetrance was doubled when the exposure was preceded by egg dechorionation (Fig. 1C), but the survival was further compromised (Fig. 1D). In both protocols, the penetrance was higher in uneclosed pupae compared to surviving adults (Fig. 1E). This indicates a stronger selection on phenotypic individuals, supporting the possibility of coupling between inductive and selective effects. We therefore adopted the exposure of intact embryos as the baseline protocol of induction. 


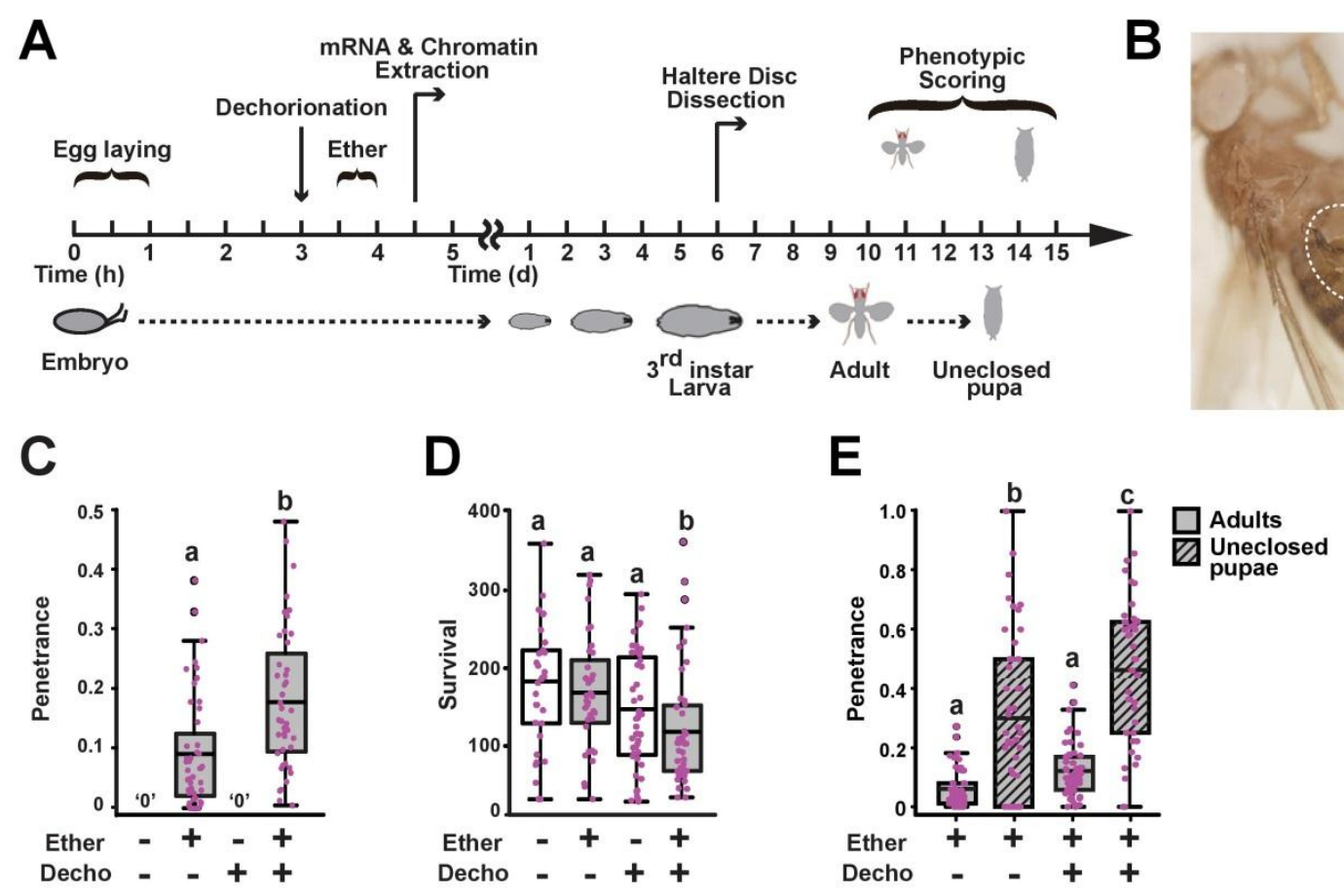

Fig. 1. Induction of bithorax phenocopy by exposure to ether vapor. (A) Flowchart of experimental procedures and measurements. (B) Representative image of severe transformation in ether-exposed flies ( $y w$ line). (C) Fractions of individuals exhibiting bithorax phenocopy (penetrance) per bottle, taking into account both uneclosed pupae and adult flies with and without ether exposure ('Ether') and egg dechorionation ('Decho'). $\mathrm{p}<0.001$, Mann-Whitney test. (D) Same as (C) for survival to the pupal stage per bottle. All statistically significant pairwise comparisons found to be $\mathrm{p}<0.05$, Two-way ANOVA followed by Tukey HSD test. The complete set of pairwise comparisons p-values is provided in Supplementary Table S1 (E) Penetrance computed separately for adult flies (grey) and uneclosed pupae (dashed grey) per bottle. All statistically significant pairwise comparisons found to be $\mathrm{p}<0.001$, a-parametric Two-way ANOVA followed by Tukey HSD test. The complete set of pairwise comparisons p-values is provided in Supplementary Table S2 (D-E) Boxplots marked with different letters are significantly different from each other whereas those possessing common letters are not ${ }^{14}$.

\section{Ether suppresses H3K4 tri-methylation, primarily in low expressed loci}

To investigate how early exposure to ether promotes homeotic transformation at a substantially later stage, we analyzed histone methylations and gene expression shortly after exposure to ether

20 (Fig. 2). Active and repressive chromatin marks were analyzed by ChIP-seq using antibodies against tri-methylated Lysine 4 (H3K4me3) and Lysine 27 (H3K27me3) of Histone 3, respectively 15. To enable comparison of H3K4me3 levels in different samples, we applied global percentile normalization of read counts for each $100 \mathrm{bp}$ region in the genome ${ }^{16}$. Comparison of these normalized counts from exposed ('Ether') vs. non-exposed embryos ('Ctrl') revealed a large (albeit not uniform) reduction in the levels of top $\mathrm{H} 3 \mathrm{~K} 4 \mathrm{me} 3$ enriched regions (Fig. 2A, Supplementary Fig. S1), but not in the H3K27me3 enriched ones (Fig. 2B, Supplementary Fig. $\mathrm{S} 1, \mathrm{~S} 2 \mathrm{~A})$. The selective effect on $\mathrm{H} 3 \mathrm{~K} 4 \mathrm{me} 3$ deposition was also reflected in the ratio between $\mathrm{H} 3 \mathrm{~K} 4 \mathrm{me} 3$ and $\mathrm{H} 3 \mathrm{~K} 27 \mathrm{me}$, as determined by integrating normalized counts over each gene region 
and dividing the H3K4me3 levels with the respective H3K27me3 levels (Fig. 2C). Overall, 88\% of the genes exhibited significant reduction in $\mathrm{H} 3 \mathrm{~K} 4 \mathrm{me} 3 / \mathrm{H} 3 \mathrm{~K} 27 \mathrm{me} 3$ ratio, versus only $5 \%$ of genes with increased ratio. In contrast to the widespread reduction of H3K4me3 mark, RNA-seq analysis showed that the difference between the transcriptional profiles of ether-exposed and nonexposed embryos, are very modest at this stage of embryonic development (Fig. 2D, Supplementary Fig. S2B, C, Supplemental Spreadsheet S1)

Since the magnitude of reduction in H3K4me3 was not uniform across all gene loci, we investigated whether this reduction correlates to methylation and/or expression levels of the respective genes at the time of exposure. For each gene, we calculated a measure of methylation retention level following Ether treatment. This was calculated as the ratio between H3K4me3 levels measured in Ether-exposed vs. non-exposed samples (Ether/Ctrl). Genes with low ratio (bottom 10\%) were denoted as 'Least retained' and genes with high ratio (top 10\%) were considered 'Most retained'. Thus the 'Least retained' group genes exhibited the strongest reduction in $\mathrm{H} 3 \mathrm{~K} 4 \mathrm{me} 3$ levels following Ether exposure, while the 'Most retained' group genes exhibited the weakest response to Ether. We then examined these distinct groups' absolute levels of methylation and expression at around the time of exposure. The group of 'Most retained' genes exhibited higher expression levels compared to the entire set of methylated genes ( $\mathrm{p}<1 \mathrm{E}-6$, bootstrap-based statistics test) (Fig. 2E), yet their methylation was significantly lower than the entire set $(\mathrm{p}<1 \mathrm{E}-6)$ (Fig. 2F). Likewise, this group is significantly enriched in the number of genes that have high expression and low H3K4 tri-methylation (Supplementary Fig. S2D, E). 'Least retained' genes, on the other hand, exhibited both lower expression and methylation levels compared to the entire set of H3K4me3 marked genes ( $p<1 \mathrm{E}-6$, bootstrap-based statistics test) (Fig. 2E and 2F, respectively). Concordantly, significant enrichment of the number of genes with low methylation and expression levels (Supplementary Fig. S2F, G) is observed. Altogether, these results indicate that retention of $\mathrm{H} 3 \mathrm{~K} 4 \mathrm{me} 3$ marks following Ether exposure correlates with the levels of expression (as opposed to methylation) at around the time of exposure (Supplementary Fig. S2H).

Next we investigated functional implications that may be associated with the non-uniform reduction of $\mathrm{H} 3 \mathrm{~K} 4 \mathrm{me} 3$ in ether-exposed embryos. Gene ontology analysis of genes with promoter regions that exhibited high levels of $\mathrm{H} 3 \mathrm{~K} 4 \mathrm{me} 3$ shortly after exposure, revealed strong enrichment of promoter regions belonging to wing development genes (Fig. 2G) and of members of various other developmental signaling pathways (Fig. 2H, Supplementary Table S3). Concordantly, analysis of the median $\mathrm{H} 3 \mathrm{~K} 4 \mathrm{me} 3$ in wing development genes revealed significantly higher levels compared to all genes following ether exposure ( $\mathrm{p}<1 \mathrm{E}-6$, bootstrap-based statistics test) (Fig. 2I). Moreover, the number of wing development genes was significantly enriched in the top 10\% of the genes ranked by H3K4me3 levels after ether exposure (Supplementary Fig. S2I).

The tendency for higher H3K4me3 levels in wing-related genes was observed with and without ether exposure ( $<<1$ E-6) (Fig. 2I, Supplementary Fig. S2I). This was confirmed by analyzing published ChIP-seq data for wild-type embryos at 0-4hr and 4-8hr stages of development ( $\mathrm{p}<1 \mathrm{E}$ 6) (Supplementary Fig. S2J). Thus, the levels of H3K4me3 at this early stage of embryonic development are preferentially higher at wing-related loci, and remain high following ether exposure. 

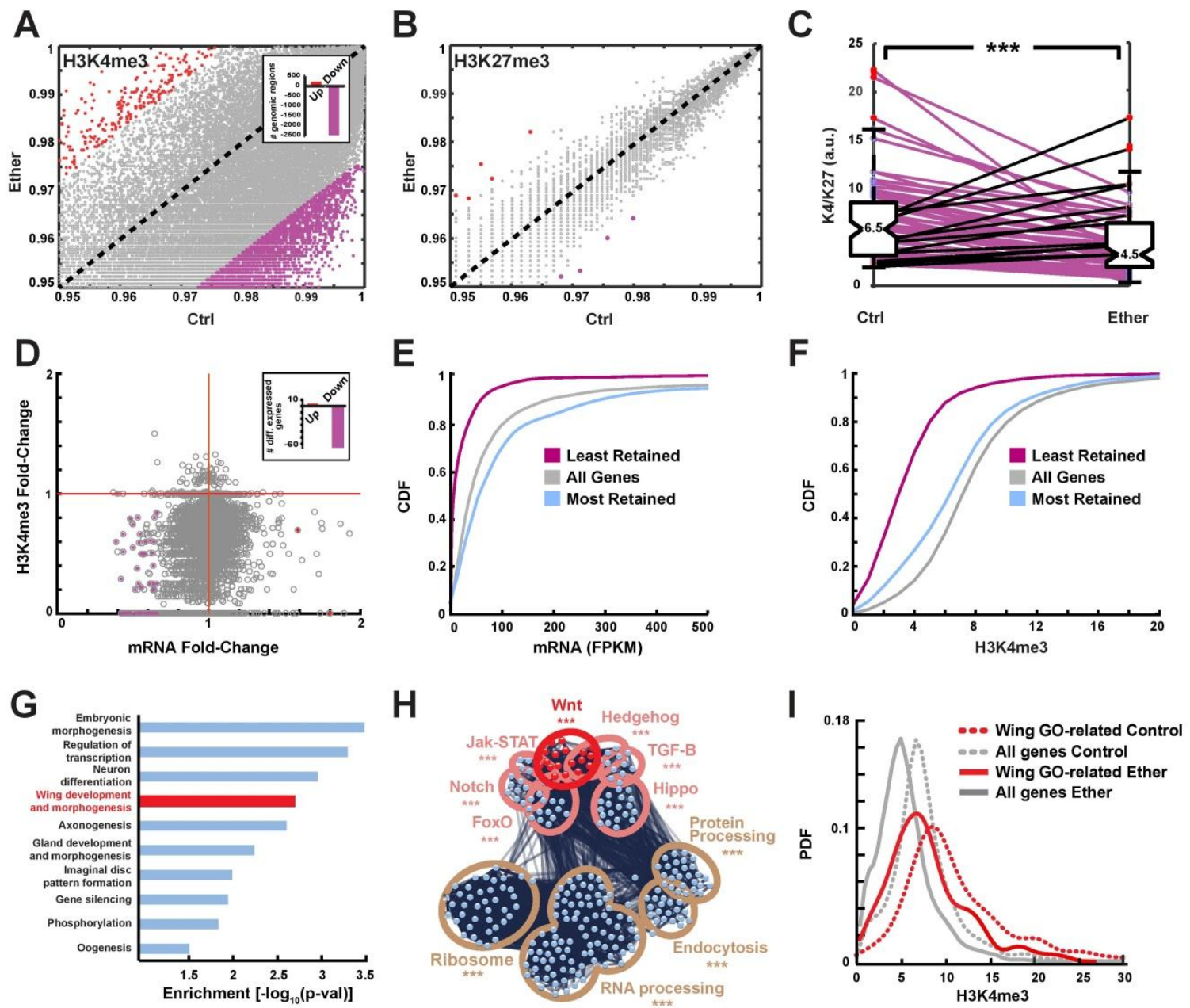

Fig. 2. Ether suppresses H3K4 tri-methylation, primarily in low-expressed loci. (A) Percentile-normalized number of H3K4me3 reads per 100bp in ether-exposed ('Ether') vs. nonexposed $y w$ embryos ('Ctrl). Red and purple dots correspond, respectively, to changes above and below two-standard deviations from the mean. Inset: numbers of regions with methylation levels above and below 2 standard deviations from the mean. (B) Same as (A) for number of H3K27me3 reads per 1000bp. (C) H3K4me3/H3K27me3 ratio per gene in ether-exposed vs. non-exposed embryos. $* * * \mathrm{p}<1 \mathrm{E}-19$, Wilcoxon signed rank test. (D) mRNA fold-change (Ether/Ctrl) vs. $\mathrm{H} 3 \mathrm{~K} 4 \mathrm{me} 3$ fold-change (Ether/Ctrl). Inset: numbers of differentially expressed genes (fold-change $>1.5$ and $\mathrm{p}<0.05$ ), based on 3 biological replicates. (E) Cumulative distributions of normalized mRNA per gene, shown for all genes with any detectable H3K4me3 (grey); and genes with 10\% highest and lowest retention of $\mathrm{H} 3 \mathrm{~K} 4 \mathrm{me} 3$ (blue and purple, respectively). (F) Same as (E) for H3K4me3 level per gene. (G) Functional enrichments of GO terms in genomic regions within the highest H3K4me3 retention levels (top 10\%). Based on 'DAVID' online tool. (H) Network analysis of the genes in (G). Significance levels are indicated in Supplementary Table S3 (I) Computed probability density of H3K4me3 levels, shown for 'wing development' genes in etherexposed embryos (solid red) and in non-exposed embryos (dotted red) vs. all genes with detectable levels of H3K4me3 in ether-exposed (solid gray) and non-exposed embryos (dotted grey). 


\section{Reduction of $t r x$ function upregulates Ubx-dependent wing genes in the haltere}

Considering the prominent enrichment of $\mathrm{H} 3 \mathrm{~K} 4 \mathrm{me} 3$ in wing-related genes and its retention upon ether exposure during embryogenesis, we sought to investigate the subsequent effects in the haltere. For that, we measured gene expression using RNA-seq in the haltere discs of $3^{\text {rd }}$ instar larvae following exposure to ether. To evaluate the potential contribution of the widespread reduction in $\mathrm{H} 3 \mathrm{~K} 4 \mathrm{me} 3$ following ether treatment to the emergence of the bithorax transformation, we also analyzed the effect of trx gene mutants which recapitulate the same phenomenon, since trx is involved in maintenance of $\mathrm{H} 3 \mathrm{~K} 4 \mathrm{me} 3$ marks and a known activator of the Bithorax gene complex (BX-C) ${ }^{11,17-19}$.

As previously reported, the reduction in trx dosage in ether-exposed flies with temperature sensitive $\operatorname{tr} x$ alleles $\left(t r x^{1+/}\right.$ and $\left.t r x^{1-/}\right)$, led to a dose-dependent increase in the bithorax penetrance (Fig. 3A, ${ }^{11}$ ). RNA-seq analysis of ether-induced changes in the haltere disc of $3^{\text {rd }}$ instar larvae revealed a substantially stronger and broader response compared to expression changes that were detected shortly after exposure. Likewise, the number of differentially expressed genes in the haltere increased with the reduction of trx dosage (Supplementary Fig. S3A, Supplemental Spreadsheet S2). In line with a 'haltere-to-wing' transformation, the group of wing development genes was significantly enriched in the set of up-regulated genes, but not at all in down-regulated genes (Fig. 3B) (no enrichments were detected in the set of down-regulated genes). In addition, the level of induction of $w g$ (a master regulator of wing development), was highly correlated with the bithorax penetrance (Fig. 3C). The inverse relation between trx dosage and wing-related gene expression in the haltere, provides a strong evidence for a causal contribution of trx function to the induction of the bithorax phenocopy.

To further examine the connection between reduced trx function and preferential up-regulation of wing-related genes, we examined ether- mediated changes in $\operatorname{tr} x$ and $U b x$, their co-factors and their downstream targets (based on ${ }^{20,21}$ ). Exposure to ether did not reduce the mRNA levels of trx and Ubx (Supplementary Fig. S3B, C) or their co-factors, including the Trx/COMPASS members, Wds, Ash2, Rbbp5, Dpy-30L1, dHCF and Menin ${ }^{1}$ and the Ubx co-factors, Extradenticle and Homothorax, which participate in Ubx repression of wing-related genes ${ }^{21,23}$ (Supplemental Spreadsheet S2). Nonetheless, the downstream targets of Ubx were highly enriched among upregulated genes (Fig. 3D) and their median mRNA levels increased by the exposure (Fig. 3E). In contrast, the changes in trx targets depend on whether or not they are also targets of Ubx. While joint targets of trx and Ubx were significantly up-regulated (Fig. 3D, E), whereas targets of trx alone were strongly down-regulated (Fig. 3D, E, inset). Similarly, wing-related genes that are also Ubx targets exhibited a strong tendency for up-regulation, while no substantial enrichments were found for wing-related genes that were trx targets but not Ubx targets (Fig. 3F, G). In summary, the strengths of enrichment and mRNA transcription levels of Ubx-regulated wing-related genes, correlate with the reduction in trx function (Fig. 3F, G).

Since $U b x$ is a trx target and a suppressor of wing genes in the haltere ${ }^{24}$, a reduction in trx function in ether-exposed embryos is fully consistent with the preferential up-regulation of wing genes that are also Ubx targets as well as with the down-regulation of trx targets that are not shared by Ubx. 

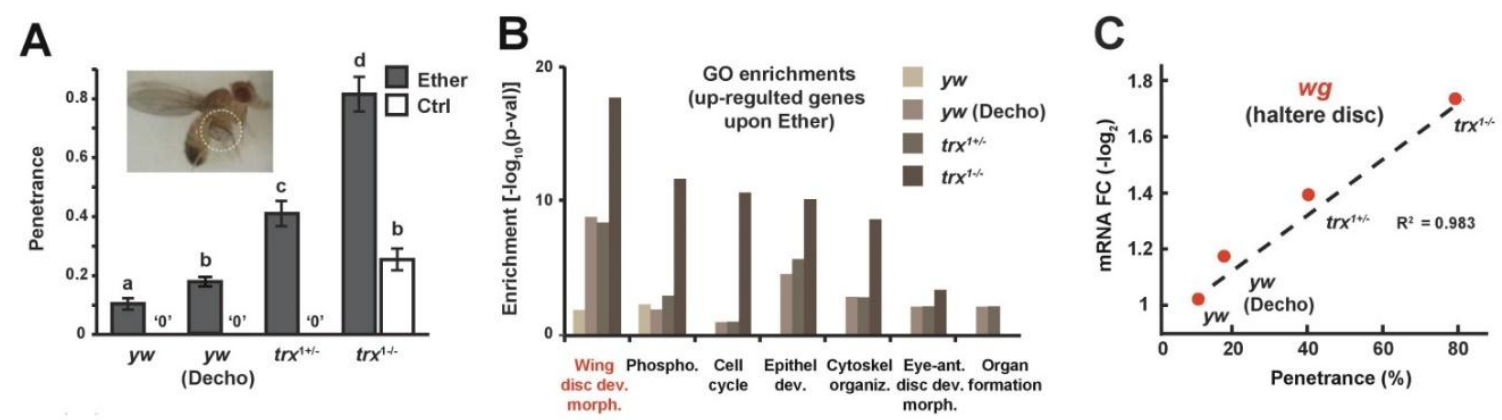

D

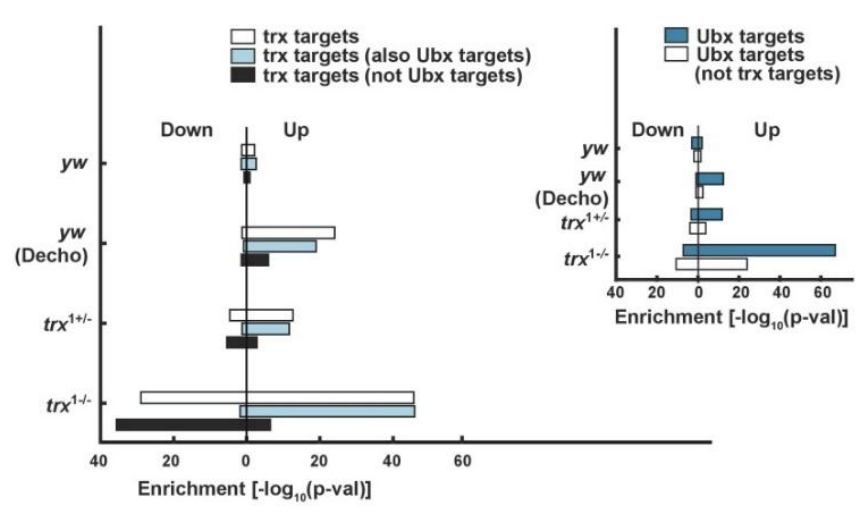

$\mathbf{F}$

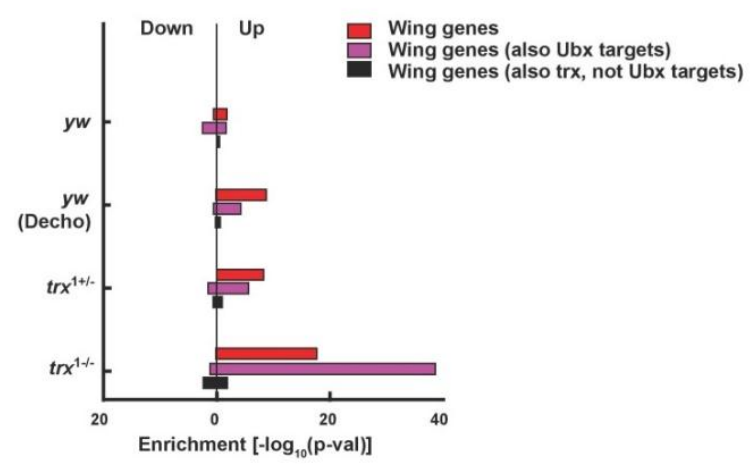

E

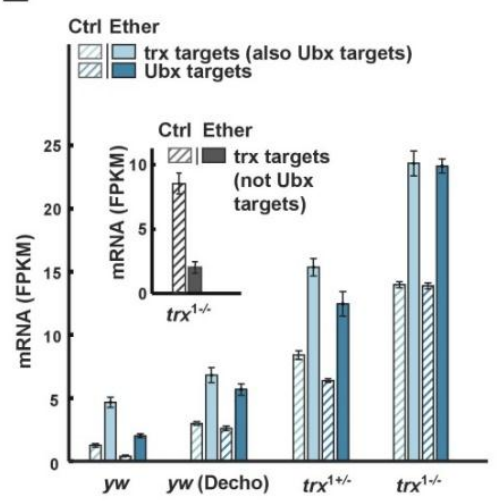

G

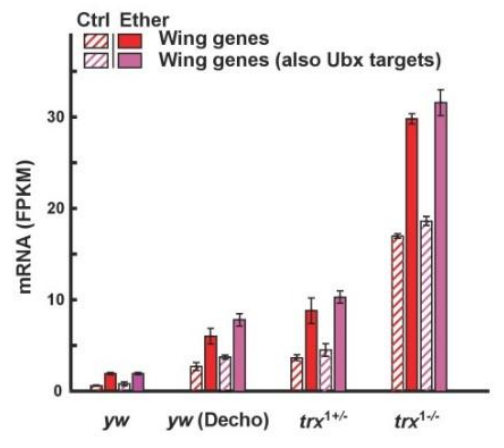

Fig. 3. Up-regulation of Ubx-dependent wing genes in the haltere is enhanced by reduction of $\operatorname{tr} x$ dosage or ether exposure. (A) Bithorax penetrance in ether-exposed and non-exposed adults and uneclosed pupae from $t r x^{1+/-}, t r x^{1--}$ and wild-type $(y w)$ with and without prior dechorionation ('Decho'). Mean penetrance per bottle \pm SE. All statistically significant pairwise comparisons found to be $\mathrm{p}<0.05$ (Supplementary Table S5), Two-way ANOVA followed by Tukey HSD test. Bars marked with different letters are significantly different from each other whereas those possessing common letters are not ${ }^{14}$. Inset: Exemplary phenocopy in a trx ${ }^{1}$ line. (B) Functional enrichments of GO terms in genes that were significantly up-regulated by ether in haltere discs of $3^{\text {rd }}$ instar larvae. Based on David online tool. (C) mRNA fold-change of wingless, $w g$, in the haltere disc following ether-exposure (vs. no exposure) of embryos. Mean fold-change (ether vs. control) for the cases in (A). (D) Enrichment of relevant subsets of trx and Ubx targets (inset) within genes that were up- and down-regulated in haltere discs of $3^{\text {rd }}$ instar larvae by embryonic exposure to ether (fold-change $>1.5$ and $p<0.05$ ), Fisher exact test. Shown for the cases in (A). (E) Average median levels of mRNA \pm SE for the relevant subsets in (D). $n=3$. Ether 
$\mathrm{p}<0.001$, Genotype $\mathrm{p}<0.001$, Ether:Genotype interaction $\mathrm{p}<0.001$, Two-way ANOVA. The complete set of ANOVA p-values is provided in Supplementary Table S6. (F, G) Same as (D, E) for wing development genes and their intersections with Ubx targets or with trx targets that are not Ubx targets. Ether $\mathrm{p}<0.001$, Genotype $\mathrm{p}<0.001$, Ether:Genotype interaction $\mathrm{p}<0.001$, Twoway ANOVA. The complete set of ANOVA p-values is provided in Supplementary Table S7.

\section{Presence of H3K4me3 at the time of exposure predisposes wing genes for up-regulation in the haltere}

In order to test whether an impaired trx function during embryogenesis could provide a causal basis for the preferential up-regulation of wing-related genes in haltere discs of $3^{\text {rd }}$ instar larvae, we evaluated the $\mathrm{H} 3 \mathrm{~K} 4 \mathrm{me} 3$ levels of the respective genes, shortly after ether exposure. We found that genes with high and low $\mathrm{H} 3 \mathrm{~K} 4 \mathrm{me} 3$ levels (top and bottom 10\%) are also expressed at high and low levels in the haltere (Fig. 4A). While this finding was equally applicable to the exposed and non-exposed cases (not shown), the genes with highest methylation after exposure (top 10\%) exhibited higher average expression in haltere of exposed case compared to the non-exposed case (Fig. 4A). Reciprocal analysis showed that genes which end up being up-regulated in the haltere disc are strongly enriched within the set of genes that had the highest H3K4me3 levels (top 10\%) shortly after the exposure (Fig. 4B). Notably, the H3K4me3 distributions corresponding to upregulated wing-related genes and Ubx targets in the haltere, were both skewed towards higher levels compared to the entire set of genes $(\mathrm{p}<1 \mathrm{E}-6$ and $\mathrm{p}<0.01$, respectively, bootstrap-based statistics test, Fig. 4C, Supplementary Fig. S4A). To further investigate how the tendency toward higher H3K4me3 levels in wing genes fits with trx function at around the time of exposure, we examined the $\mathrm{H} 3 \mathrm{~K} 4 \mathrm{me} 3$ distribution of relevant trx targets regardless of their later state of expression. We found that shortly after the exposure, the distribution of joint targets of trx and Ubx is significantly shifted towards higher levels $(\mathrm{p}<1 \mathrm{E}-5)$ while for trx targets that are not Ubx targets, it is significantly shifted towards lower levels ( $<<1 \mathrm{E}-5)$ (Fig. 4D). This was further supported by positive shift of the distribution of up-regulated joint targets of trx and Ubx compared with the entire set of genes and the negative shift of down-regulated trx targets that are not Ubx targets compared with the entire set of genes ( $p<0.01$ and $p<1 \mathrm{E}-3$, respectively) (Fig. 4D, inset, Supplementary Fig. S4B, C). Overall, these results establish a clear link between high H3K4me3 levels of Ubx targets and wing-related genes shortly after exposure and their higher levels of expression in the haltere disc of $3^{\text {rd }}$ instar larvae. This implicates that genes with early high levels of $\mathrm{H} 3 \mathrm{~K} 4 \mathrm{me} 3$ can potentially predispose the haltere towards a wing-like fate. 
A

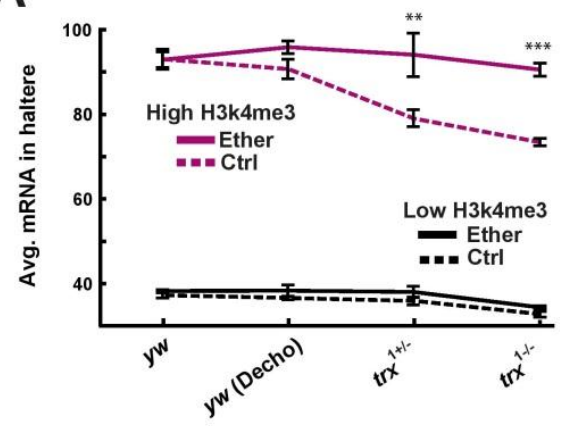

C

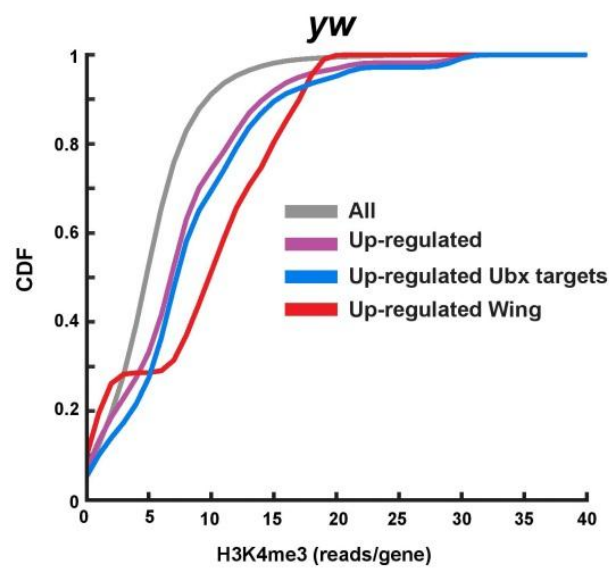

B

\begin{tabular}{|c|c|c|c|c|}
\hline & $y w$ & $y w$ (Decho) & $\operatorname{tr} x^{1+/-}$ & $\operatorname{tr} x^{1 \%}$ \\
\hline Up-regulated genes & 158 & 368 & 375 & 1129 \\
\hline \multirow{3}{*}{$\begin{array}{l}\text { Top } 10 \% \text { H3K4 } \\
\text { middle } 10 \% \text { H3K4 } \\
\text { bottom } 10 \% \text { H3K4 }\end{array}$} & $p<10^{-4}$ & $\mathrm{p}<10^{-11}$ & $p<10^{-8}$ & $p<10^{-41}$ \\
\hline & ns & ns & ns & $p<0.015$ \\
\hline & ns & ns & $p<0.019$ & ns \\
\hline Down-regulated genes & 77 & 141 & 966 & 1096 \\
\hline \multirow{3}{*}{$\begin{array}{l}\text { Top } 10 \% \text { H3K4 } \\
\text { middle } 10 \% \text { H3K4 } \\
\text { bottom } 10 \% \text { H3K4 }\end{array}$} & $p<0.003$ & ns & ns & ns \\
\hline & ns & ns & ns & ns \\
\hline & ns & ns & ns & ns \\
\hline
\end{tabular}

D

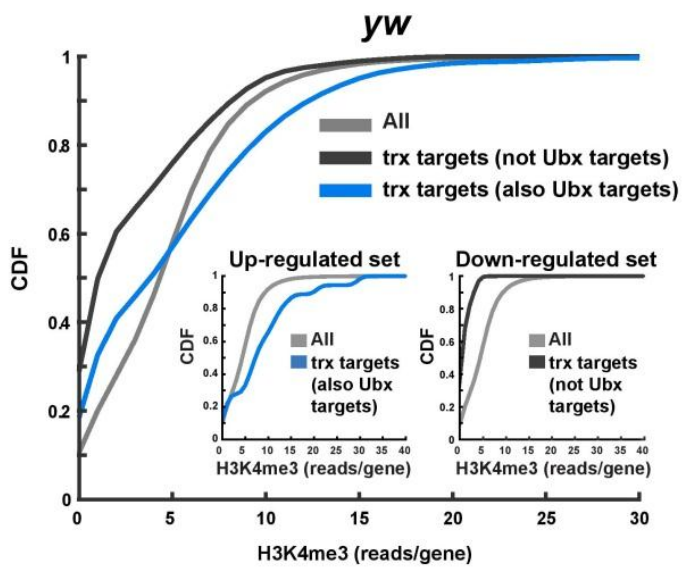

Fig. 4. Up-regulation of wing genes in the haltere correlates with high H3K4me3 at the time of exposure. (A) mRNA levels in the haltere ( $3^{\text {rd }}$ instar larvae), corresponding to genes that exhibited the highest (top 10\%, purple) and lowest (bottom 10\%, black) detectable H3K4me3 levels in $y w$ embryos after ether exposure (4.5hr AED). mRNA levels are displayed for $y w$ (with and without dechorionation), $\operatorname{tr} x^{1+/}$ and $t r x^{1+/+}$. Mean FPKM $\pm \mathrm{SE}, \mathrm{n}=3 . * * \mathrm{p}<0.01$, *** $\mathrm{p}<$ 0.001, Two-way ANOVA followed by Tukey HSD test. (B) Enrichment of overlap between $\mathrm{H} 3 \mathrm{~K} 4 \mathrm{me} 3$ levels in exposed embryos ( $y w$ line, 4.5hr AED) and differential expression (ether vs. control) in the haltere of disc of $3^{\text {rd }}$ instar larvae. Shown for the cases in (A). Hyper geometric test (C) Cumulative distributions of H3K4me3 levels, shown for up-regulated genes (purple), upregulated Ubx targets (blue), up-regulated wing development genes (red) and all genes (gray) (D) Cumulative distributions of $\mathrm{H} 3 \mathrm{~K} 4 \mathrm{me} 3$ for joint targets of trx and Ubx (blue), targets of trx that are not shared with Ubx (black) and all genes with detectable methylation (gray). Inset: Distributions of H3K4me3 levels corresponding to indicated gene targets that are subsequently up- and downregulated in the haltere disc (left and right, respectively).

\section{Double mutants of trx and $H s p 90$ exhibit spontaneous bithorax transformations}

While the reduction in trx function in response to ether can provide explanation for the bithorax transformation, it is not clear how ether exposure leads to reduction in trx function. Combining a previous report of trx function dependence on $\mathrm{Hsp} 90{ }^{25}$ with evidence for bithorax induction by early exposure to heat instead of ether ${ }^{8,26}$, suggests that $\mathrm{Hsp} 90$ could provide a link between ether exposure and reduced trx function. In line with this possibility, we found that genetic reduction 
of $H s p 90$ function in $H s p 83^{[e 6 A] /+}$ flies causes a substantial increase in the bithorax penetrance (Fig. 5A). Similar aggravation was observed in wild-type $(y w)$ flies developed from ether-exposed embryos that were pre-treated with the Hsp90 inhibitor, Geldanamycin, immediately after egg deposition (Fig. 5B). Finally, analysis of $H s p 83^{[e 6 A]} / t r x^{1}$ double heterozygotes, showed that the combined reduction of $H s p 90$ and trx dosage can give rise to bithorax phenocopy without exposure to ether (Fig. 5C). None of the single mutations, on the other hand, was able to promote spontaneous emergence of phenocopy. Altogether, these findings indicate that the bithorax response to ether involves interaction between combined reductions of $\mathrm{Hsp} 90$ and trx function. The dependence of the induced phenocopy on function of Hsp90 suggested that the transcriptional changes in the embryo might include a signature of heat-shock and/or protein folding stress response. By taking that into consideration, we found that the initial weak changes in transcription are nonetheless enriched in heat shock response genes (Fig. 5D), including genes that are assisted by Hsp90 ('Hsp90 clients', ${ }^{27}$ ) and targets of the heat sock regulator, HSF ${ }^{28,29}$. Altogether, these findings indicate a synergy between Hsp90 and trx impairment in inducing the bithorax phenotype, suggesting a possible cooperation in driving the ether response.
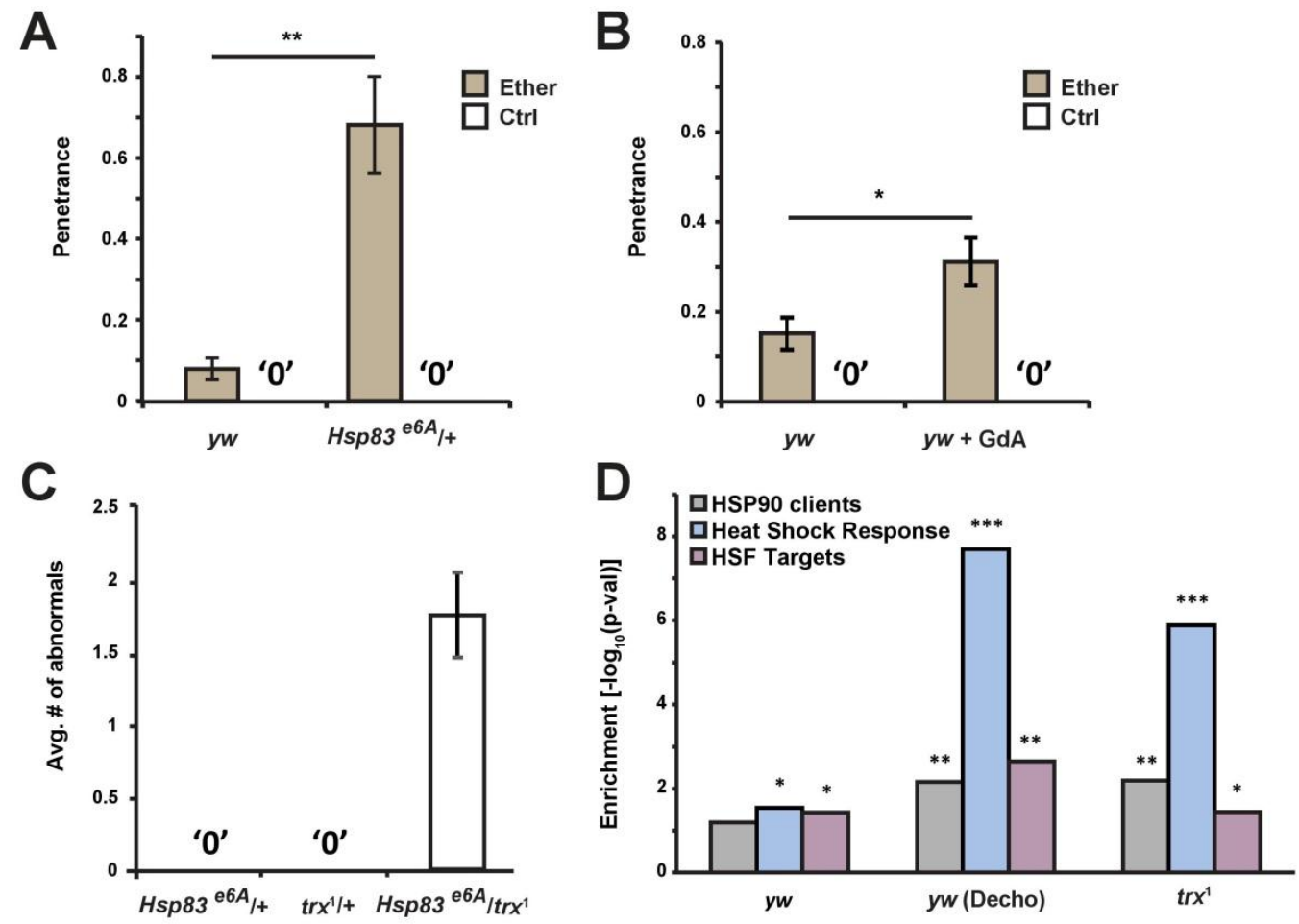

Fig. 5. Combined reduction in trx and $H s p 90$ function promotes spontaneous bithorax transformations. (A, B) Increase in ether-induced penetrance of the bithorax phenocopy, following a decrease in $H s p 90$ gene dosage $\left(H s p 83^{[e 6 \mathrm{~A}]} /+\mathrm{line}\right)(\mathrm{A})$ or pre-treatment with the Hsp90 inhibitor, Geldanamycin ('GdA') (B). Mean penetrance per bottle $\pm \mathrm{SE}$, based on 3 biological replicates. $* \mathrm{p}<0.05, * * \mathrm{p}<0.01$, Student's t-test. (C) Spontaneous haltere-to-wing transformations in $H s p 90$ and trx double mutants. Mean bithorax phenocopy \pm SE in $H \operatorname{sp} 83^{[e 6 A]} / t r x^{1}, t r x^{1} /+$ and $H s p 90^{[e 6 A]} /+$ flies. Based on 7 biological replicates. (D) Enrichment of heat shock response genes (blue), Hsp90 clients (grey) and HSF targets (purple) in differentially expressed transcripts shortly after exposure to ether vapor. ${ }^{*} \mathrm{p}<0.05, * * \mathrm{p}<0.01, * * * \mathrm{p}<0.001$. 
Ether vapor disrupts protein structure in the embryo

Considering the ability of $H s p 90$ mutation, when combined with $t r x^{1}$, to phenocopy the ether treatment, we hypothesized that these two effects might be linked. On the one hand, Hsp90 is a protein chaperone, which enables its target proteins to acquire their active conformations ${ }^{30}$. On the other hand, ether is an organic solvent and its vapor could potentially disrupt the structure of proteins in vivo. This effect, together with reduction in Hsp 90 function, may either disrupt the activity or increase the load on the Hsp90 and reduce the ability of this chaperon to support the functions of its usual clients, such as $t r x^{25}$. We evaluated this possibility by analyzing the effect of ether on the integrity of the egg and protein structure in the embryo. Inspection of embryos that were exposed to the vapor for $2 \mathrm{~h}$ revealed gross increase in egg clarity (Fig. 6A), suggesting an elevation in egg permeability and lipid precipitation. Staining of embryos with the nucleic-acid stain, Acridine Orange ${ }^{31}$ revealed increased egg permeability following exposure to ether vapor (Fig. 6B), suggesting that the vapor can also penetrate and influence internal components in the embryo. To investigate if it affects the integrity of proteins inside the embryo, we first analyzed the total embryonic proteome by (Far-UV) circular dichroism (CD) ${ }^{32,33}$. Comparison of native extracts from exposed vs. non-exposed embryos (following in-vivo exposure) revealed significant alterations in protein secondary structures, specifically $\alpha$-helices (Fig. 6C). Similarly, staining the native protein extracts with protein conformation-sensitive probe, 8-anilino-1 naphthalene sulfonate (ANS) ${ }^{34}$, revealed concordant significant differences between extracts from exposed vs. non-exposed embryos. This change in ether exposed embryos was in the same direction (albeit smaller) than was observed following embryonic exposure to heat denaturation (Fig. 6D). Finally, we employed yet another method of measuring the change in protein folding as measured by loss of fluorescence intensity in live, Histone-RFP tagged embryos. Analysis in control vs ether-treated embryos revealed a significant reduction in RFP intensity (Fig. $15 \mathrm{E}, \mathrm{F}$ ) without a change in mRNA levels of the respective Histone transcript (we could not detect any transcription at this stage of the respective Histone neither with nor without exposure). Altogether, these findings show that ether vapor indeed penetrates the embryos and interferes with protein conformation in-vivo. 

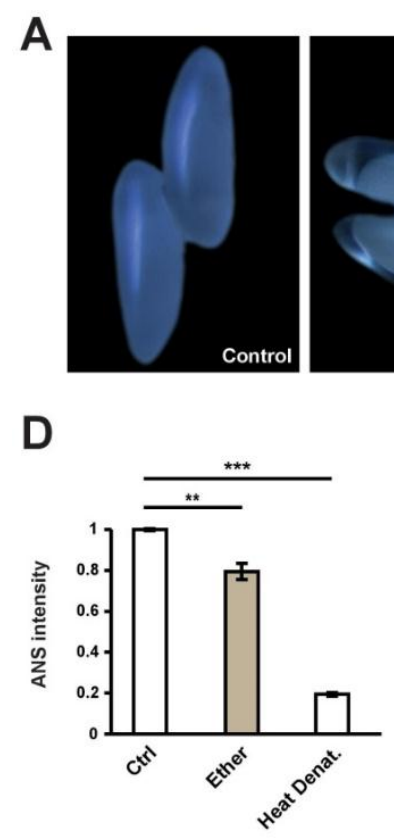

E
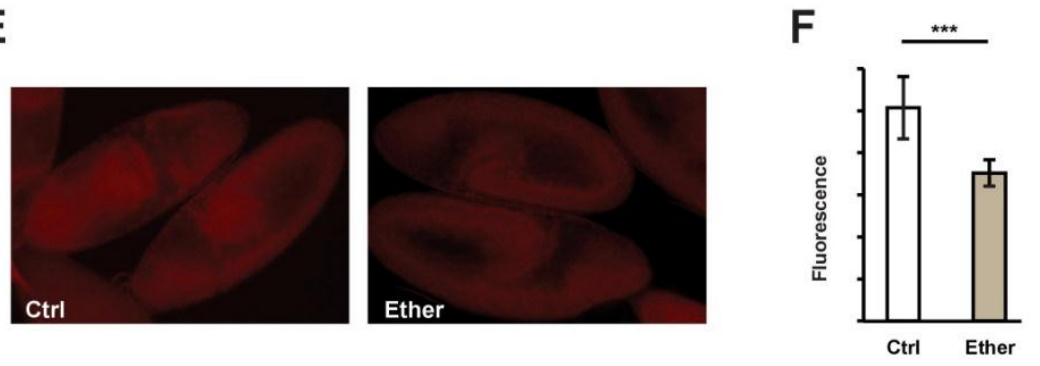

Fig. 6. Effect of ether vapor on the integrity of protein structures in the embryo. (A) Effect of ether vapor on egg perimeter and transparency. Representative images (10X) following $2 \mathrm{hr}$ of exposure vs. no exposure to ether vapor. (B) Representative images of Acridine Orange-stained $y w$ embryos for the following cases: no treatment (up left), 5 min immersion in Citrasolv® solution (up right, ${ }^{35}$ ), immersion in ether liquid for $5 \mathrm{~min}$ (bottom left) and exposure to ether vapor for 1.5hr (Bottom right). (C) Circular dichroic (Far-UV) spectra of proteins extracted from $y w$ embryos of exposure or no exposure to ether vapor (solid and dotted lines, respectively). Displayed spectra correspond to average of 3 independent measurements. $\mathrm{p}<0.05$, Student's t-test. (D) Fluorescence intensity of embryonic lysates ( $y \mathrm{w}$ line), stained with 8-anilino-1-naphthalene sulfonate (ANS), a fluorescent probe for protein conformational changes. Shown for untreated embryos (Ctrl) and embryos that were exposed to ether vapor (Ether) or heat denaturation at 80 ${ }^{\circ} \mathrm{C}$. Mean intensity $\pm \mathrm{SE}$, based on 3 biological replicates. $* * \mathrm{p}<0.01$, *** $\mathrm{p}<0.001$, One-way ANOVA following Dunnett's test. (E, F) Representative images (E) and average fluorescence intensity in His3Av-mRFP1 tagged embryos (F), with and without exposure to ether vapor. Mean intensity per embryo $\pm \mathrm{SE}, \mathrm{n}=32$ (Ctrl), $\mathrm{n}=29$ (Ether). ${ }^{* * *} \mathrm{p}<1 \mathrm{E}-4$, Mann-Whitney test.

\section{Discussion}

\section{The epigenetic basis of the induced bithorax phenocopy}

Analysis of chromatin changes shortly after exposure to ether, revealed a large decrease in H3K4me3 but not H3K27me3 marks. H3K4me3 in the Drosophila embryo is maintained by trithorax (trx) and is primarily a mark associated with the transcription start site of expressed genes ${ }^{36}$. trx is a key regulator of multiple genes, including the homeotic genes of the Antennapedia and Bithorax gene complexes e.g. Ultrabithorax, $(U b x, 37,38)$, which in turn promotes haltere fate by repressing wing genes ${ }^{24}$. Since $U b x$ and $t r x$ mutations were also implicated in homeotic aberrations of metathorax ${ }^{11,40}$ and aggravated phenocopy was observed in ether-exposed trx mutants (Fig. 4A, ${ }^{11}$ ), the global reduction in H3K4me3 suggested that ether interferes with the trithorax function. The reduced levels of $\mathrm{H} 3 \mathrm{~K} 4 \mathrm{me} 3$ in ether-exposed embryos did not lead to large changes in transcription shortly after exposure. Nonetheless, transcriptional analysis of haltere discs at a much later stage ( $3^{\text {rd }}$ instar larvae, $\sim 6$ days after ether exposure) revealed significant up- 
regulation of many wing development genes. How then the reduction in H3K4me3 in the embryo results in homeotic transformations of the haltere disc in the larva?

Joint analysis of early levels of $\mathrm{H} 3 \mathrm{~K} 4 \mathrm{me} 3$ and later gene expression in the haltere disc $\left(3^{\text {rd }}\right.$ instar larva) showed that genes with high $\mathrm{H} 3 \mathrm{~K} 4 \mathrm{me} 3$ shortly after the exposure phase tend to be highly expressed in the larval haltere. Among those genes, we found a strong enrichment for Ubx targets and wing development genes. These wing-related genes showed a significant reduction in their H3K4me3 levels upon ether exposure. However, their H3K4me3 levels were still ranked in the highest percentiles after ether exposure. In conjunction with reported positive contribution of $\mathrm{H} 3 \mathrm{~K} 4 \mathrm{me} 3$ to the maintenance of active transcriptional state, it can account for ether-induced upregulation of wing-related genes in the haltere discs of $3^{\text {rd }}$ instar larvae. This is supported by the striking distinction between trx targets based on whether or not they are also Ubx targets. Joint targets of trx and Ubx (including key wing regulators) were among the most highly H3K4 trimethylated at around the time of exposure and were also highly upregulated in the haltere disc. In contrast, trx targets that were not shared by Ubx, had low H3K4me3 levels and their expression in the haltere was indeed down-regulated by ether. Taken together, these findings demonstrate that haltere-to-wing transformation relies on up-regulation of Ubx-dependent wing regulators. These regulators are characterized by high $\mathrm{H} 3 \mathrm{~K} 4 \mathrm{me} 3$ levels at around the time of ether exposure, which predisposes them for later upregulation.

\section{Altered chaperone function as a link between ether and epigenetic state}

While the impact of ether on trx function could contribute to the emergence of haltere-to-wing transformations, it is not clear how this is caused by exposure. Several lines of evidence suggest the possibility of involvement of the heat-shock protein Hsp90 (Hsp83 in Drosophila) as a mediator of the repression of trx function by ether. Hsp90 is an essential molecular chaperone that assists in the folding of diverse proteins under stress ${ }^{30,41}$ as well as during normal ontogeny ${ }^{42}$. Hsp90 is involved in transcriptional regulation ${ }^{43,44}$, chromatin remodeling ${ }^{45,46}$ and buffering genetic and epigenetic variation ${ }^{47-51}$. Specific contributions of Hsp90 for the H3K4me3 maintenance by trx in Drosophila ${ }^{25}$ and SMYD3 in mammals have also been reported ${ }^{52}$. Moreover, it was shown that heat stress can induce phenocopies similar to ether exposure ${ }^{8,26}$. The above lines of evidence pointed to Hsp90 as a suspected mediator of a reduction in trx function in response to ether exposure. In accordance with this suggestion, we found that chemical inhibition or genetic reduction of $H s p 90$ dosage aggravate the phenotypic response to early embryonic exposure of ether vapor. Moreover, in contrast to heterozygous mutants (Hsp83/+ and trx $\left.x^{1} /+\right)$ a fraction of $H s p 83 / t_{r} x^{1}$ double heterozygous mutants exhibited bithorax phenocopy without ether exposure.

The above findings show that compromised Hsp90 function increases the bithorax sensitivity to reduction in trx function. Taking together evidence for Hsp90 contribution to H3K4me3 maintenance ${ }^{25,52}$, the disruptive impact of ether vapor on the integrity of proteins ${ }^{53-59}$ and membranes ${ }^{60}$, we suggest that $\mathrm{H} 3 \mathrm{~K} 4 \mathrm{me} 3$ reduction is caused by a decrease in the availability and/or function of Hsp90 (Fig. 7A). In support of that, we found that brief exposure to ether vapor was sufficient to penetrate the egg shell and introduce a global perturbation to protein structures. This was demonstrated by several independent methods: Altered circular dichroism (CD) signal in extracts of in-vivo exposed vs. non-exposed embryos, reduced staining of hydrophobic regions in extracts of in-vivo exposed embryos vs. non-exposed embryos and decreased RFP intensity in live, histone-RFP tagged embryos that were exposed to ether. This disruption of protein integrity 
in the embryo probably increases the load on the chaperone function and likely alters the workload profile of Hsp90.

\section{Hypothesized model for environmentally-induced homeotic transformation}

The evidence for disrupted protein structures (Fig. 6) and for bithorax-related epistasis between Hsp90 and trx functions (Fig. 5), resonates with a striking similarity between heat-induced and ether-induced phenocopies ${ }^{3,6,8,12,26}$. This includes similarity between morphogenetic changes as well as between the respective stages of sensitivity to heat and ether exposures ${ }^{5,8}$. By integrating the new findings with related evidence from previous studies, we suggest a model that can account for bithorax-like transformations in response to early embryonic exposure to either ether or heat (Fig. 7). In particular, we propose that the exposure creates proteomic stress followed by redeployment of the Drosophila Hsp90 (Hsp83), which is functionally overloaded by misfolded protein structures. The reduced availability of Hsp90 for trx at a stage in which trx function is particularly required ${ }^{61,62}$ compromises the epigenetic marking that is essential to maintain cellular identities. Genes that were more highly marked in $\mathrm{H} 3 \mathrm{~K} 4 \mathrm{me} 3$ after exposure (e.g. wing development genes) are more likely to retain an active state of expression and are therefore predisposed for high expression at a later stage of development. This pre-disposition of wing development genes enables their higher relative expression in the haltere disc of ether exposed embryos, thus promoting haltere-to-wing transformation.

In addition to providing explanation for induction of bithorax phenocopies by ether (or heat), this hypothesis can also account for the lethality of exposure at an earlier stage and the lack of responsiveness to exposure a few hours later (Fig. 7B). Previous work showed that the induction of bithorax phenocopies by either ether or heat shock is largely confined to a time window which opens shortly before cellularization and ends at around the stage of partial invagination of the anterior and posterior midgut ${ }^{5,6,8}$. Exposure during syncytial stages ( $<2 \mathrm{hr}$ AED) leads to complete embryonic lethality, while exposure after furrow formation ( $>4 \mathrm{hr}$ AED) is no longer capable of inducing a phenocopy. In between, the survival increases as a function of the onset of exposure, while the penetrance increases to a peak at around the end of cellularization and gradually decreases at later onsets of exposure (Fig. 7B). This phenomenology is fully consistent with the hypothesized involvement of Hsp90 and trx functions; early embryonic stages are characterized by rapid divisions of nuclei within a large cytoplasmic compartment. This cytoplasm is initially loaded with very high levels of maternal transcripts of Hsp90 (modENCODE data, ${ }^{63}$ ) which contributes to protein folding and functional integrity in this large compartment. This function of Hsp90 may be particularly critical for maintaining the cytoplasmic protein gradients that specify the anterior-posterior and lateral-ventral axes ${ }^{65}$. Since the interruption of these gradients is lethal ${ }^{66}$, a sufficient disruption of the integrity of proteins that contribute to the patterning can account for the lethality of exposure at that stage (Fig. 7B). This was indeed supported by the two categories of defects that have been observed in the case of early exposure ${ }^{6}$, namely: (i) failure to form a blastoderm, resulting in an undifferentiated-like mass with no recognizable structures and (ii) 40 emergence of anterior, posterior or segmentation defects that are eventually followed by failure to hatch. The abnormalities were also more pronounced in embryos that were exposed at progressively earlier stages ${ }^{6}$.

The phenotypic responsiveness, in turn, exhibits non-monotonic stage dependence which is consistent with the requirement for trx function at that particular stage ${ }^{61,62}$ and is accounted for by 45 the hypothesized model. The latter proposes that the pre-disposition for haltere-to-wing transformation depends on having sufficient levels of H3K4me3 preferentially in wing genes at 
around the time of exposure to ether. Analysis of published H3K4me3 time series data ${ }^{67}$, shows that the early $\mathrm{H} 3 \mathrm{~K} 4 \mathrm{me} 3$ levels in Ubx targets and wing development gene loci are indeed higher than the median for the entire set of methylated genes. The differential accumulation of H3K4me3 in these wing-related genes begins at the late stage of syncytial blastoderm with the onset of the bithorax sensitivity window (Fig. 7b). The establishment of a Trithorax-based epigenetic memory is thought to depend on a sufficiently long duration of $\operatorname{trx}$ association with the respective gene locus ${ }^{68,69}$. Stable propagation of the active chromatin states may therefore require a sufficient dosage of functional trx protein ${ }^{5,25,62}$. The ether (or heat)-mediated repression of $\operatorname{tr} x$ function can then lead to reduced expression stability preferentially for genes that were not sufficiently marked by trithorax function prior or during the exposure. The initially higher levels of H3K4me3 at Ubx target and wing gene loci therefore contributes to relatively higher expression stability, which is fully consistent with their later tendency of being up-regulated compared to other genes. This effect may act in concert with the determination of imaginal disc precursors from ectodermal cells, which takes place soon after cellular blastoderm formation ${ }^{70-74}$.

According to the proposed model, the predisposition towards higher relative levels of wing development genes is caused by impairment in trx function. This bias is gradually reduced as the onset of exposure gets closer to sufficient $\mathrm{H} 3 \mathrm{~K} 4 \mathrm{me} 3$ at these loci, thus reducing the efficacy of induction. This is consistent with the observation that the end of the bithorax responsiveness window coincides with the end of critical requirement for $\operatorname{trx}$ function ${ }^{11,61,75}$ as well as with a reported halt in accumulation of $\mathrm{H} 3 \mathrm{~K} 4 \mathrm{me} 3$ across the genome (Fig. 7b) ${ }^{67}$. Since re-deployment of Hsp90 and reduction in $\mathrm{H} 3 \mathrm{~K} 4$ tri-methylation are expected in ether and heat exposures, the proposed model also accounts for the striking overlap between the respective windows of responsiveness.

The hypothesized model therefore suggests the following axis of influence: Early exposure $\rightarrow$ reduced integrity of proteins $\rightarrow$ altered deployment or function of Hsp90 $\rightarrow$ compromised trx function $\rightarrow$ altered profile of $\mathrm{H} 3 \mathrm{~K} 4 \mathrm{me} 3 \rightarrow$ predisposition for upregulation of Ubx targets and wing regulators $\rightarrow$ homeotic transformations. The increased homeotic sensitivity to reduction of Hsp90 and trx functions, likely applies to additional inductions of homeotic transformations ${ }^{11,49}$ and can be utilized for fate manipulation and/or regeneration at the levels of tissues and organs. 


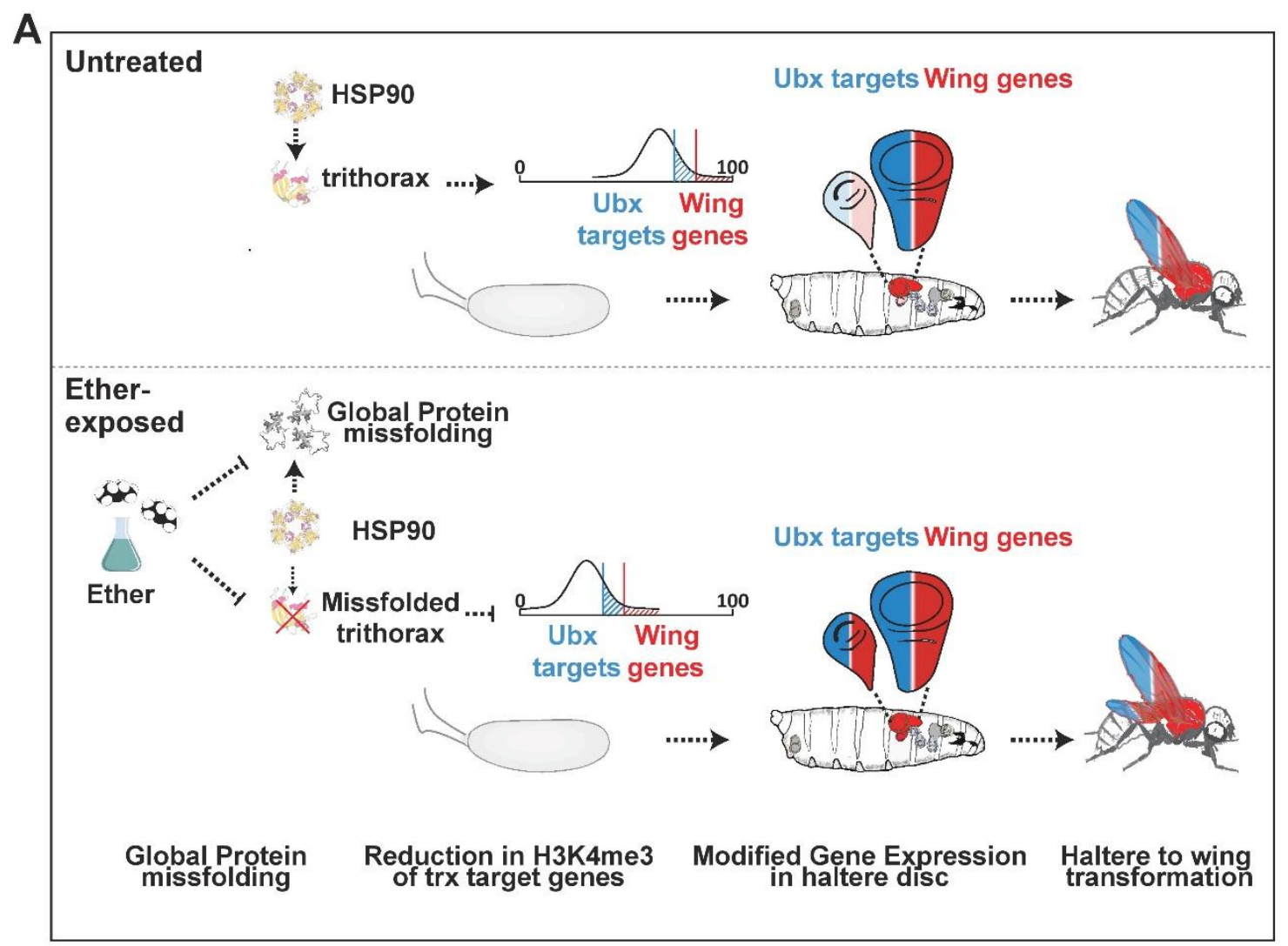

B

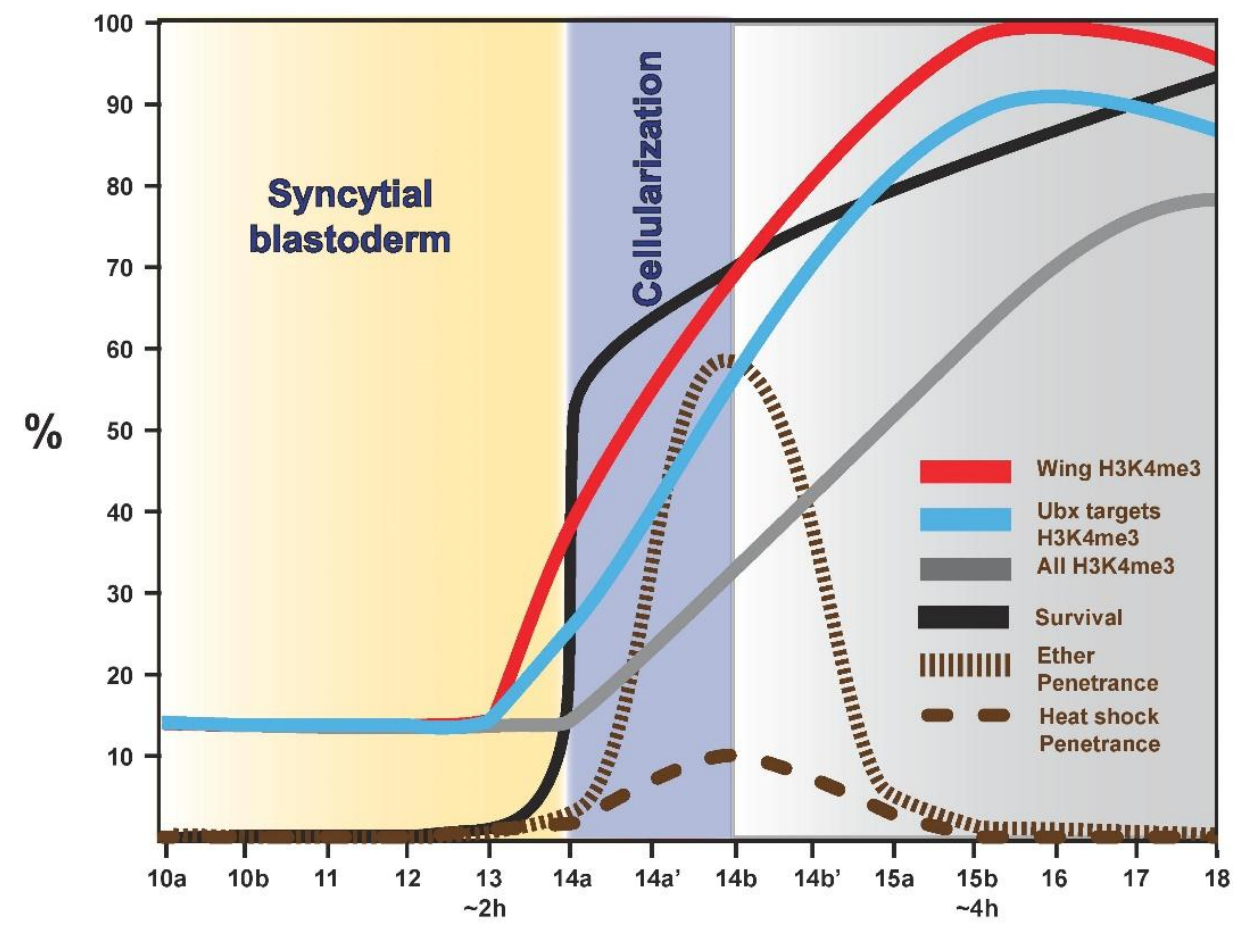

Drosophila Embryogenesis stage

Fig. 7. Hypothetical model of induced bithorax phenocopies. (A) Early exposure to ether vapor leads to protein misfolding, thus increasing the chaperonic load, including on Hsp90. 
Redeployment of Hsp90 towards misfolded proteins interferes with its contribution to trx function thereby compromising the establishment of H3K4me3 marks. When the exposure is applied shortly after the onset of $\mathrm{H} 3 \mathrm{~K} 4$ tri-methylation, some of the gene loci have already been partially methylated. Gene loci with $\mathrm{H} 3 \mathrm{~K} 4 \mathrm{me} 3$ marks prior to exposure remain more highly methylated after the exposure compared to genes that were not initially methylated. The set of genes with preferentially higher $\mathrm{H} 3 \mathrm{~K} 4 \mathrm{me} 3$ levels at the time of exposure is highly enriched with Ubx targets, which include those key wing development genes that are normally repressed by Ubx. The differentially higher $\mathrm{H} 3 \mathrm{~K} 4 \mathrm{me} 3$ levels of these genes maintain their expression, thereby predisposing them for higher relative expression during later stages of development. On the one hand, this pre-disposition of wing development genes, allows their expression in the haltere disc through trx maintenance. On the other hand, factors which normally act during haltere development to suppress wing fate might be reduced through decrease in their $\mathrm{H} 3 \mathrm{~K} 4$ tri-methylation. Together, this leads to wing-related genes not being repressed, thus promoting haltere-to-wing transformation. (B) Consistency of the hypothetical model with multiple lines of independent evidence. The lethality of exposure during most the syncytial period ${ }^{5,6,8}$ is fully in line with increased sensitivity to protein integrity in the egg cytoplasm due to increased permeability of the ether vapor in the uncellularized embryo. The increase in frequency of bithorax induction when the exposure is applied after stage 13 may be explained by the differential priming of $\mathrm{H} 3 \mathrm{~K} 4 \mathrm{me} 3$ across loci. Ubx targets, specifically wing development genes start accumulating H3K4me3 early in embryogenesis (modENCODE data ${ }^{67}$ ). Therefore, after ether exposure, these loci are expected to retain partial levels of this marking. Conversely, genes with initially insufficient levels of H3K4 tri-methylation are likely to lose their marking. Similarly, the higher survival and lack of phenocopies when the exposure is applied after stage $15 \mathrm{a}^{5,6,8}$, are consistent, respectively, with the substantial, genome-wide establishment of $\mathrm{H} 3 \mathrm{~K} 4 \mathrm{me} 3$ marks prior to exposure ${ }^{67}$. The increased sensitivity to exposure during syncytial stages and the differential methylation "window of opportunity' also apply in the case of exposure to heat, thus accounting for the similarities in the effective stages and morphogenetic outcomes. The nomenclature of the developmental stages corresponds to that described by ${ }^{8}$. 


\section{Materials and Methods}

\section{Drosophila stocks}

Drosophila lines $t r x^{l} / T M 1, H s p 83^{e 6 A}$ were obtained from the Bloomington Stock Center. The $y w$ stock was obtained from the laboratory of Prof. Eli Arama (Weizmann Institute of Science, Israel).

\section{Generation of $\operatorname{trx}^{1 / T M 6 B}, \mathrm{~Tb}$ flies}

We have replaced the third chromosome balancer of the original line $\operatorname{trx}^{l} / T M 1$ with a Tm6b balancer carrying a larval marker $(\mathrm{Tb})$ to have the ability to differentiate between homozygous and heterozygous larvae. We have restored the genetic background of the original line ${ }^{11}$, excluding the Tm6b, using chromosomal markers.

\section{Food preparation}

$\begin{array}{lcccc}\text { Standard cornmeal food } & \text { (Bloomington } & \text { Stock } & \text { Center } & \text { recipe, } \\ \text { http://flystocks.bio.indiana.edu/Fly_Work/media-recipes/molassesfood.htm). }\end{array}$

\section{Exposure and scoring of responses to ether}

0-3 day old flies were reared on fly medium supplemented with dry yeast for 3 days under $12 \mathrm{~h}$ light/dark cycle regime, temperature of $25^{\circ} \mathrm{C}$ and $70 \%$ humidity. About 10,000 adult flies were taken for 5 rounds of egg deposition, $1 \mathrm{~h}$ each, in cages on a $10 \mathrm{~cm}$ agar plate supplemented with dry yeast. The first two rounds of egg deposition were discarded for embryo's developmental stage synchronizations. Dechorionation was performed $2 \mathrm{~h}$ later, using 3\% sodium hypochlorite for 2.5 min. Following 2.5-3.5h after oviposition ${ }^{5}$, at the embryonic syncytial blastoderm stage, the eggs were exposed to ether. Eppendorf tube containing $1.5 \mathrm{ml}$ of diethyl ether was placed in each glass bottle, allowing the ether vapor to diffuse and exposing the embryos to a fixed concentration of ether vapor in $25^{\circ} \mathrm{C}$ for $30 \mathrm{~min}$. Then, tubes containing the remaining ether liquid were removed and the bottles with the embryos were left to evaporate any ether remains. For embryonic RNA and ChIP analyses, 3:45-4:45 h old embryos were collected and flash freezed in liquid nitrogen. For haltere disc RNA analysis and phenocopy scoring, embryos were transferred to new clean bottles and allowed to hatch. We have dissected haltere discs from 3rd stage larvae developed from ether exposed and non-exposed embryos. Phenocopy scoring was done every day from the first day of eclosion till 5 days later. After the fifth day all unenclosed pupae were dissected and presence of phenocopy was determined. For Hsp90 inhibition experiments, embryos were dechorionated immediately after oviposition and rocked in PBS supplemented with Geldanamycin $(35 \mu \mathrm{M})$ for $1 \mathrm{~h}^{35}$.

\section{Chromatin immunoprecipitation (ChIP) and ChIP-seq}

Ether exposed and non-exposed embryos (3:45-4:45h old) were collected (0.1 mg per group). Embryos were crosslinked in $1 \mathrm{ml} \mathrm{A} 1$ buffer $(60 \mathrm{mM} \mathrm{KCl}, 15 \mathrm{mM} \mathrm{NaCl}, 15 \mathrm{mM}$ HEPES [pH 7.6], $4 \mathrm{mM} \mathrm{MgCl} 2,0.5 \%$ Triton X-100, $0.5 \mathrm{mM}$ dithiothreitol (DTT), and complete EDTAfree protease inhibitor cocktail [Roche]), in the presence of $1.8 \%$ formaldehyde and homogenized at the same time in a douncer followed by incubation for $15 \mathrm{~min}$ at room temperature. Crosslinking was stopped by adding $225 \mathrm{mM}$ glycine followed by incubation for $5 \mathrm{~min}$. The homogenate was transferred to a $1 \mathrm{ml}$ tube and centrifuged for $5 \mathrm{~min}, 4,000 \mathrm{x} \mathrm{g}$ at $4{ }^{\circ} \mathrm{C}$. The supernatant was discarded, and the nuclear pellet was washed three times in $3 \mathrm{ml} \mathrm{A} 1$ buffer and once in $3 \mathrm{ml}$ of A2 buffer (140 mM NaCl, 15 mM HEPES [pH 7.6], 1 mM EDTA, 0.5mMEGTA, 1\%Triton X-100, 
$0.5 \mathrm{mMDTT}, 0.1 \%$ sodium deoxycholate, and protease inhibitors) at $4^{\circ} \mathrm{C}$. After the washes, nuclei were resuspended in $\mathrm{A} 2$ buffer in the presence of $0.1 \%$ SDS and $0.5 \% \mathrm{~N}$-lauroylsarcosine and incubated for $30 \mathrm{~min}$ on a rotating wheel at $4{ }^{\circ} \mathrm{C}$. Chromatin was sonicated using a Bioruptor (Diagenode) for $15 \mathrm{~min}$ (settings 30s on, 30s off, high power). Sheared chromatin had an average length of 300 to 700 base pairs. After sonication and $10 \mathrm{~min}$ high-speed centrifugation, fragmented chromatin was recovered in the supernatant. Chromatin was precleared by addition of $50 \mu l$ of Protein A-Agarose (PA) suspension (Roche 11134515001) followed by overnight incubation at $4^{\circ} \mathrm{C}$. PA was removed by centrifugation, antibodies at dilution 1:100 were added to the supernatant (a control in the presence of rabbit preserum [Mock IP] was performed at the same time), and samples were incubated for $4 \mathrm{hr}$ at $4^{\circ} \mathrm{C}$ in a rotating wheel. PA $(50 \mu \mathrm{l})$ was added, and incubation was continued overnight at $4^{\circ} \mathrm{C}$. Antibody-protein complexes were collected by centrifugation at 4,000 rpm for $1 \mathrm{~min}$, and the supernatants were discarded. Samples were washed four times in A3 (A2+ $0.05 \%$ SDS) buffer and twice in $1 \mathrm{mM}$ EDTA, $10 \mathrm{mM}$ Tris (pH 8) buffer (each wash, 5 min at 4C). Chromatin was eluted from PA in $250 \mu 1$ of $10 \mathrm{mM}$ EDTA, 1\% SDS, $50 \mathrm{mM}$ Tris (pH 8) at $65^{\circ} \mathrm{C}$ for $15 \mathrm{~min}$, followed by centrifugation and recovery of the supernatant. The eluate was incubated overnight at $65^{\circ} \mathrm{C}$ to reverse crosslinks and treated with Proteinase $\mathrm{K}$ for $3 \mathrm{hr}$ at $50^{\circ} \mathrm{C}$. Sodium acetate $(110 \mu \mathrm{M})$ was added to the samples, phenol-chloroform extracted, and ethanol precipitated in the presence of $20 \mu \mathrm{g}$ glycogen. DNA was resuspended in $100 \mu \mathrm{l}$ of water. Deep sequencing analysis of DNA was performed by Fasteris SA (Geneva, Switzerland) ChIP-seq library preparation was performed with illumina TruSeq ChIP kit. Adaptors were removed from raw FASTQ reads with cutadapt. The reads were then aligned to drosophila genome (UCSC dm3) with bowtie2; samtools and bedtools were used to convert resulting SAM files to the required downstream formats (bedraph etc.). We performed the analysis via the "Misha" R package ${ }^{76}$. The signal was smoothed via moving window averaging over $100 \mathrm{bp}$ followed by global percentile normalization. Next a 95\% threshold was applied to separate signal from the background.

\section{RNA-seq library preparation and sequencing}

The cDNA libraries were prepared from poly-A mRNA following the manufacturer's instructions in the Illumina RNA sample preparation kit. In short, poly (T) oligo-attached magnetic beads were used to purify the poly(A)-containing mRNA molecules. The mRNA was fragmented into 200 to $500 \mathrm{bp}$ segments. RNA fragments were converted into cDNA using SuperScript II reverse transcriptase (Life Technology) and random hexamer primers. Adaptors were ligated to the cDNA fragments, followed by purification, PCR and additional purification. Deep sequencing measurement of RNA was performed in the Genomics Core Facility unit of the Technion Genome Center, Technion -Israel Institute of Technology (Haifa, Israel) using Illumina Genome Analyzer IIx (GA IIx). For sequencing, we used the following experimental kits and reagents: 1) Standard Cluster Generation Kit (\#GD-103-4001, Illumina, San Diego, CA, USA) containing all reagents necessary to load the samples on to the flow cell and perform the bridge amplification, 2) Illumina Sequencing Kit v5 (TruSeq SBS Kit v5 GA (36-cycles), FC-104-5001) which contains the reagents for the sequencing runs, and 3) the GA IIx Sequencing Control Software version SCS 2.8, which was used to control the sequencer. Sequencing was based on 50bp single-end reads. mRNA was barcoded in the ligation step by Illumina standard multiplex adaptors. The multiplexed samples were sequenced on a single lane to yield between 2 and 8 million reads per sample. 


\section{RNA-seq analysis}

Adaptors were removed from sequence reads using the cutadapt program ${ }^{77}$. Reads were mapped to the drosophila transcriptome (Ensembl version BDGP.25) using Bowtie2 and TopHat software ${ }^{78}$, then Cufflinks and Cuffmerge ${ }^{78}$ were applied to define a list of transcripts that are comparable between all samples. Differentially expressed transcripts including fold-change and statistics were identified by applying the DESeq $\mathrm{R}$ package ${ }^{79}$ on the bowtie 2 output.

GO enrichments were computed using the 'DAVID' online resource ${ }^{80,81}$ with cutoffs for up/down regulation and FDR set to 1.5 -fold and 0.05 , respectively. Up- and down-regulated gene-sets were analyzed separately.

\section{Eggshell permeabilization}

Several hundred of $y w$ adult flies were synchronized twice for $1 \mathrm{~h}$ and allowed to lay eggs for $1 \mathrm{~h}$ on a $10 \mathrm{~cm}$ agar plate. Eggs were collected from the plate, washed in water, dechorionated and immersed in Citrasolv ${ }^{\circledR}$ (Citra Solv, Danbury, Connecticut)(1:10 dilution, 5 min), diethyl ether ( $5 \mathrm{~min}$ ) or were exposed to diethyl ether vapors for $1.5 \mathrm{~h}$ in a closed bottle. Control embryos were left untreated in a closed bottle for the same period of time. Then the embryos were stained with Acridin orange dye for 5 minutes. Images were taken using a fluorescent stereoscope LEICA MZ16F equipped with Nikon digital sight DS-Fil camera.

\section{Circular dichroism and Fluorescence Spectroscopy}

CD spectra were recorded on a Chirascan spectropolarimeter (Applied Photophysics) calibrated with a solution of ammonium d-10-camphorsulfonate. Far-UV CD spectra were acquired using 1mm path-length cuvettes, a step size of $0.5 \mathrm{~nm}$, a bandwidth of $1 \mathrm{~nm}$, and a time constant of $1 \mathrm{~s}$. Protein concentration was $0.4 \mathrm{mg} / \mathrm{mL}$.

Fluorescence emission (0.1-0.4 mg/mL protein, $25^{\circ} \mathrm{C} ; \lambda \mathrm{ex}=380 \mathrm{~nm}, \lambda \mathrm{em}=545 \mathrm{~nm}$ for unbound dye and $\lambda \mathrm{em}=470 \mathrm{~nm}$ for the dye-protein complex) were recorded with a Cytation5 (BioTek) plate reader fluorimeter in standard 96-well plate. In the experiments conducted in the presence of 8-Anilinonaphthalene-1-sulfonic acid (ANS) (1 mM; protein concentration, $0.1-0.4 \mathrm{mg} / \mathrm{mL}$ ) the excitation wavelength was $380 \mathrm{~nm}$. Before recording, the proteins were let to interact with the dye for $1 \mathrm{~h}$. Following acquisition, both experiments (CD and fluorescence) were corrected for buffer (and dye, in the experiments involving ANS) contributions, averaged, and smoothed using sliding windows of $1.5 \mathrm{~nm}$ (far- and near-UV CD) or $3 \mathrm{~nm}$ (fluorescence).

\section{Quantification of RFP Fluorescence}

Several hundred of His3Av-mRFP1 adult flies were synchronized twice for $1 \mathrm{~h}$ and allowed to lay eggs for $1 \mathrm{~h}$ on a $10 \mathrm{~cm}$ agar plate. Eggs were collected from the plate, washed in water, dechorionated and exposed to ether as previously described. Eggs were then transferred to MatTek Glass-Bottom Dishes that were pre-treated with embryo glue (3 M tape in Heptane) and covered in Halocarbon oil 700 (Sigma). The eggs were imaged using UPLSAPO $20 \times$ numerical aperture: 0.75 objective of the confocal OLYMPUS FV1000 microscope with temperature-controlled chamber (set at $25^{\circ} \mathrm{C}$ ) and IX81 ZDC Motorized Stage. Image analysis was performed using ImageJ.

\section{Statistical analyses}

Statistical tests were performed using MATLAB (MathWorks) and R statistical program ${ }^{82}$. The significant difference between a subset group of genes to the entire population in their $\mathrm{H} 3 \mathrm{~K} 4 \mathrm{me} 3$ or mRNA levels was numerically calculated using a bootstrap-based statistical test, as follows: 
this test was based on repeated cycles $(1,000,000)$ of selecting genes at random from the total set of genes (same sample size as the subset group) and counting the fraction of times, in which the median methylation/expression in this random selection exceeds or fell behind the median level of the true subset. Significance was determined based on the percentage of iterations in which this analytical p-value was equal to, lower or higher than the median of the total set of genes. Analysis of enrichment of gene ontology annotations in sets of up- and down-regulated genes was done using the DAVID web tool with Benjamini correction for multiple hypothesis testing ${ }^{80,81}$

Data availability: ChIP-seq and RNA-seq data generated in this study have been deposited in the SRA database (http://www.ncbi.nlm.nih.gov/sra) under accession number SUB4002129. 


\section{References}

1. Schuettengruber, B., Bourbon, H.-M., Croce, L. Di \& Cavalli, G. Genome Regulation by Polycomb and Trithorax: 70 Years and Counting. (2017). doi:10.1016/j.cell.2017.08.002

2. Steffen, P. a \& Ringrose, L. What are memories made of? How Polycomb and Trithorax proteins mediate epigenetic memory. Nat. Rev. Mol. Cell Biol. 15, 340-56 (2014).

3. Gloor, H. Phänokopie-Versuche mit äther an Drosophila. rev. Suisee Zool. 54, 673-712 (1947).

4. Waddington, C. H. GENETIC ASSIMILATION OF THE BITHORAX PHENOTYPE. Evolution (N. Y). 10, 1-13 (1956).

5. Capdevila, M. . \& Garcia-Bellido, A. Development and genetic analysis of bithorax phenocopies in Drosophila. Nature (1974).

6. Bownes, M. \& Seiler, M. Developmental effects of exposing Drosophila embryos to ether vapour. J. Exp. Zool. 199, 9-23 (1977).

7. Capdevila, M. P. \& Garcia-Bellido, A. Phenocopies of Bithorax mutants. Dev. Genes Evol. 185, 105-126 (1978).

8. Santamaria, P. Heat Shock Induced Phenocopies of Dominant Mutants of the Bithorax Complex in Drosophila melanogaster. Molec. gen. Genet 172, 161-163 (1979).

9. Ho, M., Tucker, C., Keeley, D. \& Saunders, P. Effects of successive generations of ether treatment on penetrance and expression of the bithorax phenocopy in Drosophila melanogaster. J. Exp. ... 225, 357-368 (1983).

10. Gibson, G. \& Hogness, D. S. Effect of polymorphism in the Drosophila regulatory gene Ultrabithorax on homeotic stability. Science 271, 200-203 (1996).

11. Ingham, P. \& Whittle, R. Trithorax: A new homoeotic mutation of Drosophila melanogaster causing transformations of abdominal and thoracic imaginal segments. Molec Gen Genet 179 SRC-, 607-614 (1980).

12. Waddington, C. Genetic Assimilation of the Bithorax Phenotype. Evolution (N. Y). 10, 113 (1956).

13. Morata, G. \& Gareia-Bellido, A. Analysis of Some Mutants of the Bithorax System of Drosophila. Wilhelm Roux's Arch. 179, 125-143 (1976).

14. Piepho, H.-P. An Algorithm for a Letter-Based Representation of All-Pairwise Comparisons. Journal of Computational and Graphical Statistics 13, 456-466 (2004).

15. Schuettengruber, B. et al. Functional Anatomy of Polycomb and Trithorax Chromatin Landscapes in Drosophila Embryos. PLoS Biol. 7, e1000013 (2009). 
16. Schuettengruber, B. et al. Cooperativity, Specificity, and Evolutionary Stability of Polycomb Targeting in Drosophila. Cell Rep. 9, 219-233 (2014).

17. Breen, T. R. \& Harte, P. J. trithorax regulates multiple homeotic genes in the bithorax and Antennapedia complexes and exerts different tissue-specific, parasegment-specific and promoter-specific effects on each. Development 117, 119-134 (1993).

18. Capdevila, M. P. \& Garcia-Bellido, A. Genes involved in the activation of the bithorax complex ofDrosophila. Wilhelm Roux's Arch. Dev. Biol. 190, 339-350 (1981).

19. Shearn, A., Hersperger, E. \& Hersperger, G. Genetic studies of mutations at two loci of Drosophila melanogaster which cause a wide variety of homeotic transformations. Roux's Arch. Dev. Biol. 196, 231-242 (1987).

20. Slattery, M., Ma, L., Negre, N., White, K. P. \& Mann, R. S. Genome-wide tissue-specific occupancy of the hox protein ultrabithorax and hox cofactor homothorax in Drosophila. PLoS One 6, (2011).

21. Choo, S. W., White, R. \& Russell, S. Genome-Wide Analysis of the Binding of the Hox Protein Ultrabithorax and the Hox Cofactor Homothorax in Drosophila. PLoS One 6, e14778 (2011).

22. Choo, S. W., White, R. \& Russell, S. Genome-Wide Analysis of the Binding of the Hox Protein Ultrabithorax and the Hox Cofactor Homothorax in Drosophila. PLoS One 6, e14778 (2011).

23. Chan, S.-K., Jaffe, L., Capovilla, M., Botas, J. \& Mann, R. S. The DNA binding specificity of ultrabithorax is modulated by cooperative interactions with extradenticle, another homeoprotein. Cell 78, 603-615 (1994).

24. Weatherbee, S. D., Halder, G., Kim, J., Hudson, A. \& Carroll, S. Ultrabithorax regulates genes at several levels of the wing-patterning hierarchy to shape the development of the Drosophila haltere. Genes Dev. 12, 1474-1482 (1998).

25. Tariq, M., Nussbaumer, U., Chen, Y., Beisel, C. \& Paro, R. Trithorax requires Hsp90 for maintenance of active chromatin at sites of gene expression. Proc. Natl. Acad. Sci. 106, 1157-1162 (2009).

26. Maas, A. Uber die Auslosbarkeit von Temperatur-Modifikationen wahrend der Embryonalentwicklung von Drosophila melanoguster. 516-572 (1948).

27. Hartson, S. D. \& Matts, R. L. Approaches for defining the Hsp90-dependent proteome. Biochim. Biophys. Acta - Mol. Cell Res. 1823, 656-667 (2012).

28. Gonsalves, S. E., Moses, A. M., Razak, Z., Robert, F. \& Westwood, J. T. Whole-Genome Analysis Reveals That Active Heat Shock Factor Binding Sites Are Mostly Associated with Non-Heat Shock Genes in Drosophila melanogaster. PLoS One 6, e15934 (2011). 
29. Duarte, F. M. et al. Transcription factors GAF and HSF act at distinct regulatory steps to modulate stress-induced gene activation. Genes Dev. 30, 1731-46 (2016).

30. Taipale, M., Jarosz, D. F. \& Lindquist, S. HSP90 at the hub of protein homeostasis:emerging mechanistic insights. Nat. Publ. Gr. (2010). doi:10.1038/nrm2918

31. Bradley, D. E. Staining of Bacteriophage Nucleic Acids with Acridine Orange. Nature 205, 1230-1230 (1965).

32. Bentz, H., Bachinger, H. P., Glanville, R. \& Kuhn, K. Physical Evidence for the Asembly of A and B Chains of Human Placental Collagen in a Single Triple Helix. Eur. J. Biochem. 92, 563-567 (1978).

33. Greenfield, N. J. Using circular dichroism spectra to estimate protein secondary structure. Nat. Protoc. 1, 2876-90 (2006).

34. Semisotnov, G. V. et al. Study of the ?molten globule? intermediate state in protein folding by a hydrophobic fluorescent probe. Biopolymers 31, 119-128 (1991).

35. Rand, M. D., Kearney, A. L., Dao, J. \& Clason, T. Permeabilization of Drosophila embryos for introduction of small molecules. Insect Biochem. Mol. Biol. 40, 792-804 (2010).

36. Bernstein, B. E. et al. Methylation of histone H3 Lys 4 in coding regions of active genes. Proc. Natl. Acad. Sci. U. S. A. 99, 8695-700 (2002).

37. Castelli-Gair, J. E. \& Garcia-Bellido, A. Interactions of Polycomb and trithorax with cis regulatory regions of Ultrabithorax during the development of Drosophila melanogaster.; Interactions of Polycomb and trithorax with cis regulatory regions of Ultrabithorax during the development of Drosophil. EMBO J. 913, 4267-4275 (1990).

38. Chang, Y. L., King, B. O., O’Connor, M., Mazo, a \& Huang, D. H. Functional reconstruction of trans regulation of the Ultrabithorax promoter by the products of two antagonistic genes, trithorax and Polycomb. Mol. Cell. Biol. 15, 6601-6612 (1995).

39. Castelli-Gair, J. E., Garcia-Bellido, A. \& García-Bellido, A. Interactions of Polycomb and trithorax with cis regulatory regions of Ultrabithorax during the development of Drosophila melanogaster. EMBO J 9, 4267-4275 (1990).

40. Bridges, C. B. \& Morgan, T. H. The third-chromosome group of mutant characters of Drosophila melanogaster. Carnegie Inst. Washingt. Publ. 327, 1-251 (1923).

41. Lindquist, S. THE HEAT-SHOCK RESPONSE. Ann. Rev. Biochem 55, 1151-91 (1986).

42. Calderwood, S. K., Khaleque, M. A., Sawyer, D. B. \& Ciocca, D. R. Heat shock proteins in cancer: chaperones of tumorigenesis. Trends Biochem. Sci. 31, 164-172 (2006).

43. Prodromou, C. Mechanisms of Hsp90 regulation. Biochem. J. 473, 2439-2452 (2016). 
44. Khurana, N. \& Bhattacharyya, S. Hsp90, the Concertmaster: Tuning Transcription. Front. Oncol. 5, (2015).

45. Ruden, D. M. \& Lu, X. Hsp90 affecting chromatin remodeling might explain transgenerational epigenetic inheritance in Drosophila. Curr. Genomics 9, 500-508 (2008).

46. Sawarkar, R. \& Paro, R. Hsp90@ chromatin.nucleus: an emerging hub of a networker. Trends Cell Biol. 23, 193-201 (2013).

47. Rutherford, S. L. \& Lindquist, S. Hsp90 as a capacitor for morphological evolution. Nature 396, 336-342 (1998).

48. Queitsch, C., Sangster, T. A. \& Lindquist, S. Hsp90 as a capacitor of phenotypic variation. Nature 417, 618-624 (2002).

49. Sollars, V. et al. Evidence for an epigenetic mechanism by which Hsp90 acts as a capacitor for morphological evolution. Nat. Genet. 33, 70-74 (2003).

50. Wong, K. S. \& Houry, W. A. Hsp90 at the crossroads of genetics and epigenetics. Cell Res. 16, 742-749 (2006).

51. Sangster, T. A. et al. HSP90-buffered genetic variation is common in Arabidopsis thaliana. Proc. Natl. Acad. Sci. 105, 2969-2974 (2008).

52. Hamamoto, R. et al. SMYD3 encodes a histone methyltransferase involved in the proliferation of cancer cells. Nat. Cell Biol. 6, 731-740 (2004).

53. Ueda, I. \& Okumura, F. Effects of chloroform, diethyl ether and a propiophenone derivative, 3-dimethylamino-2-methyl-2-phenoxypropiophenone hydrochloride, upon cyclic 3',5'-nucleotide phosphodiesterase. Biochem. Pharmacol. 20, 1967-1971 (1971).

54. Ueda, I. \& Chiou, J.-S. Arrhythmogenic Effect of Inhalation Anesthetics: Biochemical Heterogeneity between Conduction and Contractile Systems and Protein Unfolding. 31, 223-233 (1994).

55. Middleton, A. J. \& Smith, E. B. General anaesthetics and bacterial luminescence II. The effect of diethyl ether on the in vivo light emission of Vibrio fischeri. Proc. R. Soc. London B Biol. Sci. 193, (1976).

56. Young, A. P., Brownt, F. F., Halseyi, M. J. \& Sigman, D. S. Volatile anesthetic facilitation of in vitro desensitization of membrane-bound acetylcholine receptor from Torpedo californica (mechanism of general anesthesia/ligand-induced conformational change/protein-lipid interactions). Neurobiology 75, 4563-4567 (1978).

57. Normann, P. T., Ripel, A. \& Mørland, J. Diethyl ether inhibits ethanol metabolism in vivo by interaction with alcohol dehydrogenase. Alcohol. Clin. Exp. Res. 11, 163-6 (1987). 
58. Hemmings, H. C. \& Adamo, A. I. Effects of halothane and propofol on purified brain protein kinase C activation. Anesthesiology 81, 147-55 (1994).

59. Slater, S. J. et al. Inhibition of protein kinase C by alcohols and anaesthetics. Nature 364, 82-84 (1993).

60. Franks, N. P. \& Lieb, W. R. Molecular mechanisms of general anaesthesia. Nature 300, 487-493 (1982).

61. Sedkov, Y., Tillib, S., Mizrokhi, L. \& Mazo, a. The bithorax complex is regulated by trithorax earlier during Drosophila embryogenesis than is the Antennapedia complex, correlating with a bithorax-like expression pattern of distinct early trithorax transcripts. Development 120, 1907-17 (1994).

62. Ingham, P. W. A clonal analysis of the requirement for the trithorax gene in the diversification of segments in Drosophila. Embryol. exp. Morph 89, 349-365 (1985).

63. Arbeitman, M. N. et al. Gene expression during the life cycle of Drosophila melanogaster. Science (80-. ). 297, 2270-2275 (2002).

64. Arbeitman, M. N. et al. Gene expression during the life cycle of Drosophila melanogaster. Science (80-. ). 297, 2270-2275 (2002).

65. Driever, W. \& Nüsslein-Volhard, C. A gradient of bicoid protein in Drosophila embryos. Cell 54, 83-93 (1988).

66. Manseau, L. J. \& Schüpbach, T. The egg came first, of course! Trends Genet. 5, 400-405 (1989).

67. Li, X., Harrison, M., Villalta, J., Kaplan, T. \& Eisen, M. Establishment of regions of genomic activity during the Drosophila maternal to zygotic transition. Elife (2014).

68. Alabert, C. et al. Two distinct modes for propagation of histone PTMs across the cell cycle. Genes Dev. 29, 585-590 (2015).

69. Petruk, S. et al. TrxG and PcG proteins but not methylated histones remain associated with DNA through replication. Cell 150, 922-933 (2012).

70. Garcia-Bellido, A. \& Merriam, J. R. Cell lineage of the imaginal discs inDrosophila gynandromorphs. J. Exp. Zool. 170, 61-75 (1969).

71. Wieschaus, E. \& Gehring, W. Clonal analysis of primordial disc cells in the early embryo of Drosophila melanogaster. Dev. Biol. 50, 249-263 (1976).

72. Wieschaus, E. \& Gehring, W. Gynandromorph analysis of the thoracic disc primordia inDrosophila melanogaster. Wilhelm Roux's Arch. Dev. Biol. 180, 31-46 (1976).

73. Lohs-Schardin, M., Cremer, C. \& Nu“sslein-Volhard, C. A fate map for the larval 
epidermis ofDrosophila melanogaster: localized cuticle defects following irradiation of the blastoderm with an ultraviolet laser microbeam. Dev. Biol. 73, 239-255 (1979).

74. Lohs-Schardin, M., Sander, K., Cremer, C., Cremer, T. \& Zorn, C. Localized ultraviolet laser microbeam irradiation of early Drosophila embryos: Fate maps based on location and frequency of adult defects. Dev. Biol. 68, 533-545 (1979).

75. Ingham, P. W. trithorax and the regulation of homeotic gene expression in Drosophila: a historical perspective. Int. J. Dev. Biol. 42, 423-429 (1998).

76. Schuettengruber, B. et al. Cooperativity, Specificity, and Evolutionary Stability of Polycomb Targeting in Drosophila. Cell Rep. 9, 219-233 (2014).

77. Martin, M. Cutadapt removes adapter sequences from high-throughput sequencing reads. EMBnet.journal 17, 10 (2011).

78. Trapnell, C. et al. Differential gene and transcript expression analysis of RNA-seq experiments with TopHat and Cufflinks. Nat. Protoc. 7, 562-78 (2012).

79. Anders, S. \& Huber, W. Differential expression analysis for sequence count data. Genome Biol. 11, R106 (2010).

80. Huang, D., Sherman, B. \& Lempicki, R. Systematic and integrative analysis of large gene lists using DAVID bioinformatics resources. Nat. Protoc. (2009).

81. Huang, D., Sherman, B. \& Lempicki, R. Bioinformatics enrichment tools: paths toward the comprehensive functional analysis of large gene lists. 37, 1-13 (2009).

82. Core Team, R. R: A language and environment for computing. R Foundation for Statistical Computing. (2015).

Funding: This work was supported by the Sir John Templeton Foundation (grant ID: \#40663). Author contributions: Conceptualization, O.S., M.E. and Y.S.; Methodology, O.S., M.E. and Y.S; Validation, O.S. and M.E; Formal Analysis, O.S., S.D, and M.E; Investigation, O.S., M.E., F.C., S.D, I.A. and E.S.; Data Curation, O.S. and M.E; Writing - Original Draft, O.S., M.E. and Y.S.; Writing - Review \& Editing, F.C., G.C., O.S., M.E., and Y.S.; Funding Acquisition, Y.S.; Supervision, O.S. and M.E; Project Administration, O.S.; 


\section{Supplementary:}

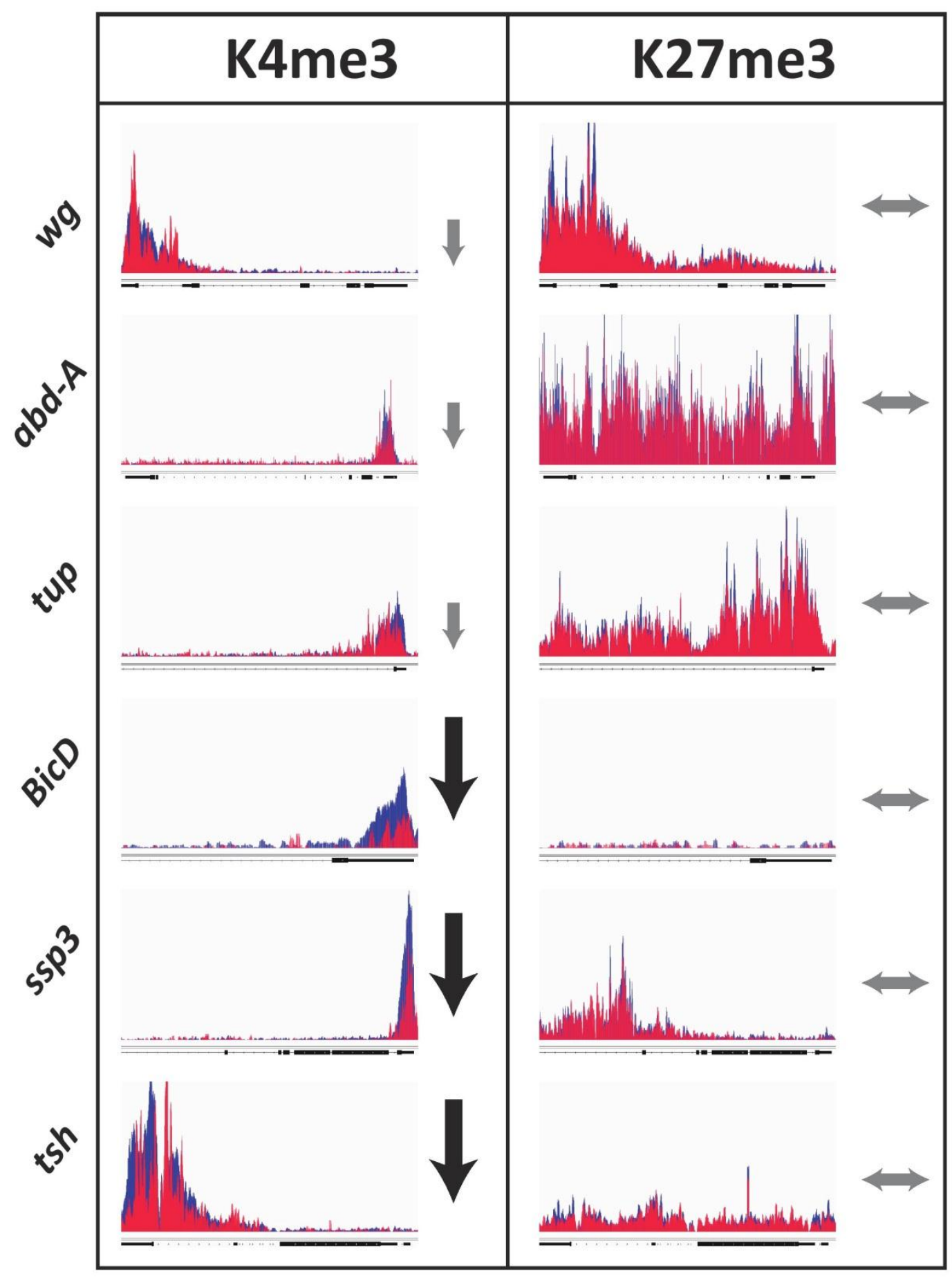

Fig. S1. Representative ChIP- seq profiles. Related to Figure 2. wg, abd-A, tup, BicD, ssp3 and $t s h$ in ether-exposed (red) and non-exposed embryos (blue). Left and right panels correspond to $\mathrm{H} 3 \mathrm{~K} 4 \mathrm{me} 3$ and H3K27me3 marks, respectively. Vertical arrows indicating reduction in number of reads, while horizontal arrows indicating a lack of change. 
A

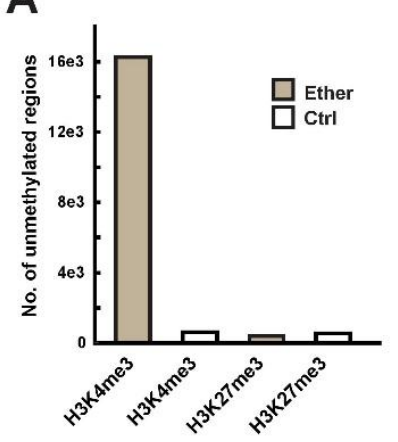

B

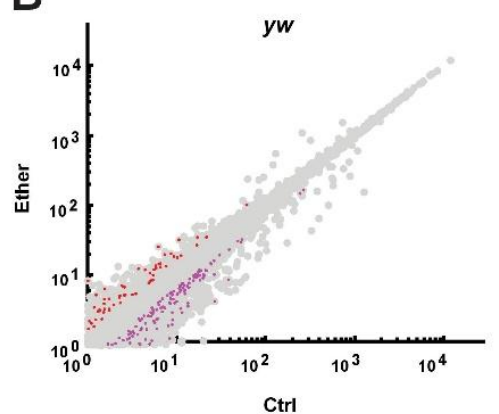

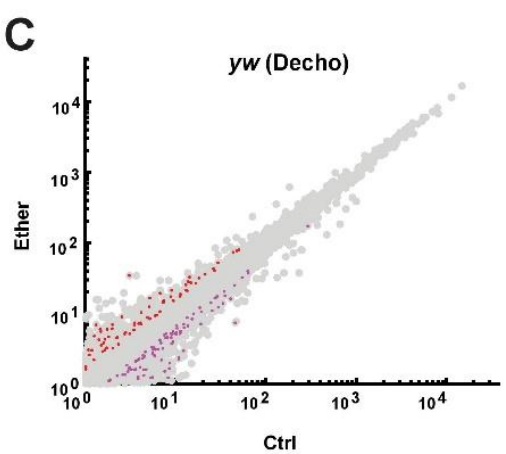
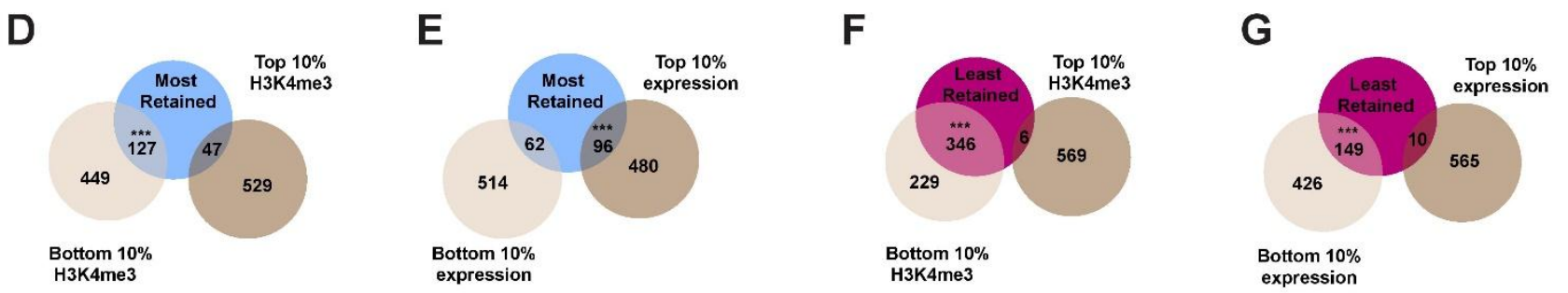

H

I
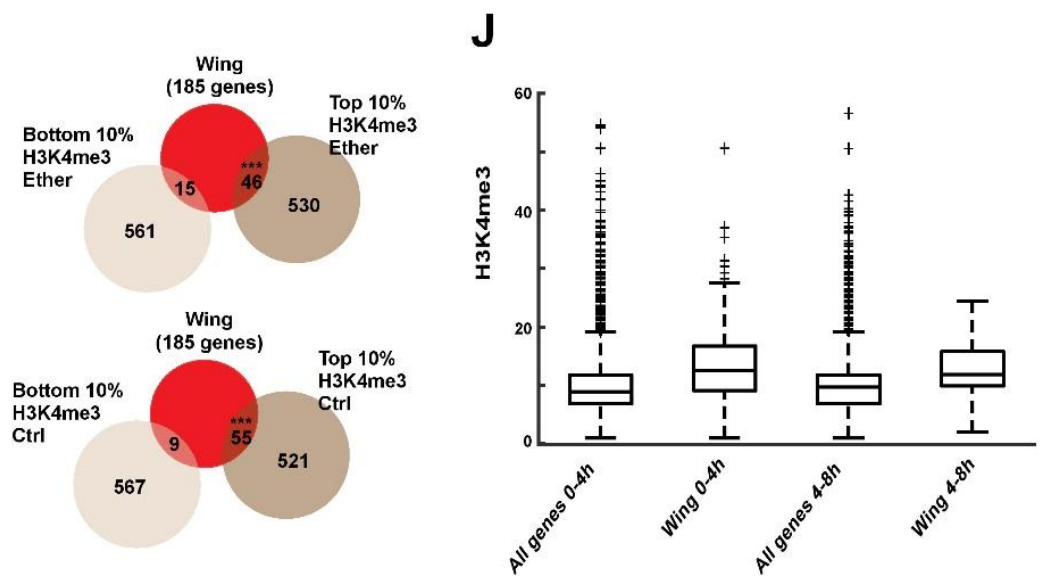

Fig. S2. Ether suppresses H3K4 tri-methylation, primarily in low-expressed loci. Related to Figure 2. (A) Normalized numbers of genomic regions with H3K4 and H3K27 tri-methylation (100bp and 1000bp long, respectively), measured for ether-exposed and control embryos $(y w)$. (B, C) mRNA levels for etherexposed and control embryos, with and without dechorionation ( $\mathrm{C}$ and $\mathrm{B}$, respectively). Differential expression (absolute fold-change $>1.5, \mathrm{p}<0.05, \mathrm{n}=3$ ) is indicated by red and purple overlays. (D) Intersection between genes with high preferential retention of $\mathrm{H} 3 \mathrm{~K} 4 \mathrm{me} 3$ marks ('Most retained') and genes with the highest and lowest H3K4me3 levels in control embryos (top and bottom 10\%). *** $\mathrm{p}<1 \mathrm{E}-19$, hypergeometric test. (E) Same as (D) for intersection with genes with highest and lowest expression in control embryos. *** p < 1E-7. (F, G) Same as (D and E) for intersection of 'Least retained' genes. *** $\mathrm{p}$ $<1 \mathrm{E}-137$ and $\mathrm{p}<1 \mathrm{E}-22$, respectively. (H) Median mRNA (solid line) and H3K4me3 levels (dashed line) for genes with high, medium and no preferential retention. (I) Intersection between wing disc development genes and genes with highest and lowest $\mathrm{H} 3 \mathrm{~K} 4 \mathrm{me} 3$ levels (top and bottom 10\%) shortly after exposure to ether and without. *** $\mathrm{p}<1 \mathrm{E}-8$, *** $\mathrm{p}<1 \mathrm{E}-14$, respectively. hypergeometric test. (J) Box plots of H3K4me3 read counts corresponding to two time intervals of embryonic development $(0-4 \mathrm{hr}$ and $4-8 \mathrm{hr}$ AED). Displayed for all genes and wing development genes ('Wing') based on compilation of ModEncode data ${ }^{67}$. 
A

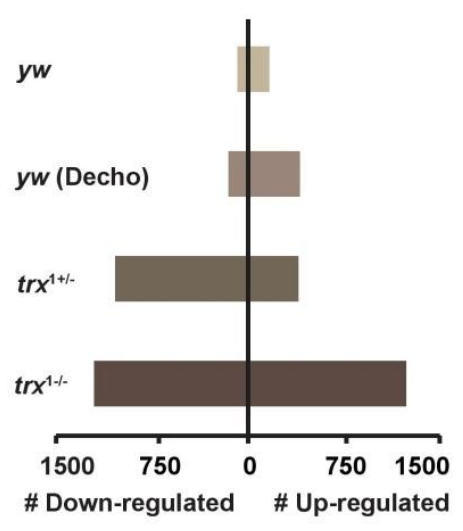

C

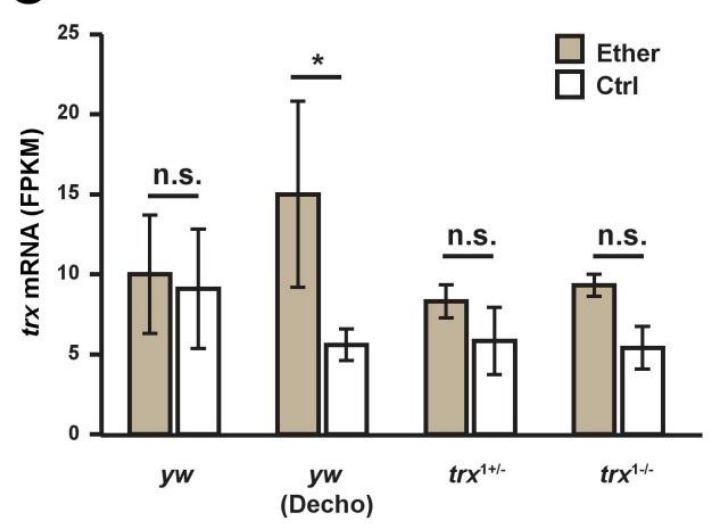

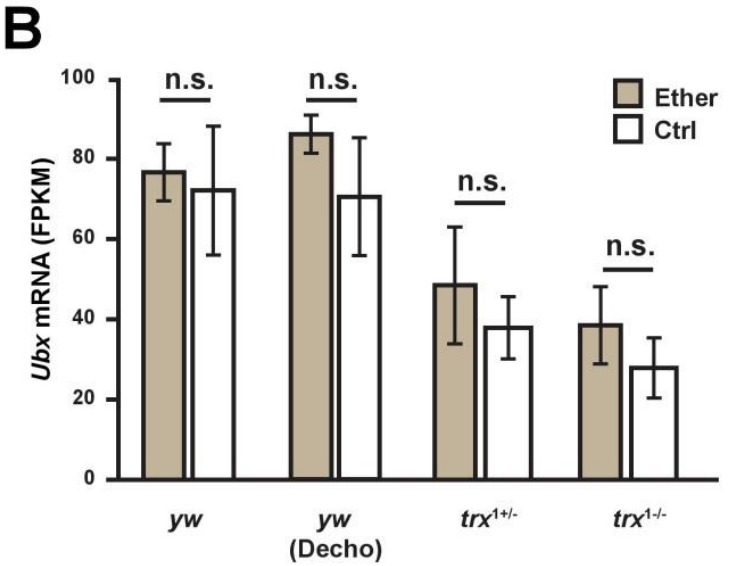

D

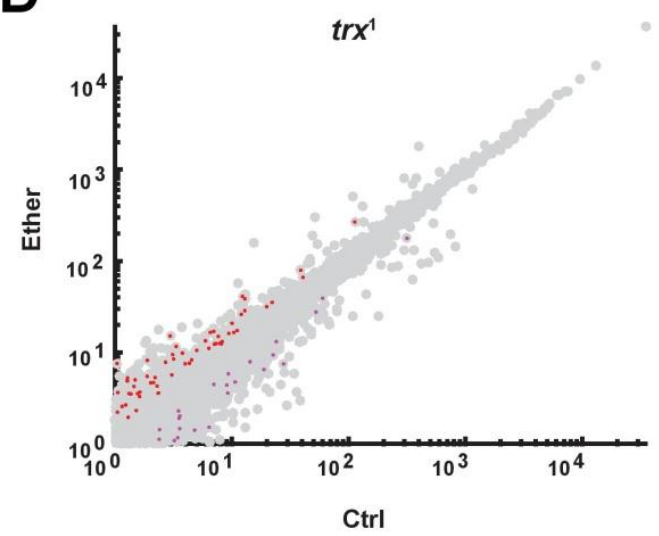

Fig. S3. Related to Figure 3. (A) Number of differentially expressed genes (absolute fold-change $>1.5, \mathrm{p}<0.05, \mathrm{n}=3$ ) in ether-exposed $y w, y w$ decho, $t r x^{1+-}$ and $t r x^{l-/}$ haltere imaginal discs. (B) Ubx mRNA in ether-exposed $y w, y w$ decho, $t r x^{1+-}$ and $t r x^{l--}$ haltere imaginal discs Average \pm SE, $\mathrm{n}=3$. Two-way ANOVA following Tukey HSD test. (C) Same as (B) for $\operatorname{trx}$ mRNA. Two-way ANOVA following Tukey HSD test. (D) mRNA levels in $t r x^{l}$ embryo shortly after exposure to ether vs. control. Differential expression (absolute fold-change $>1.5, \mathrm{p}<0.05, \mathrm{n}=3$ ) is indicated by red and purple overlays. 

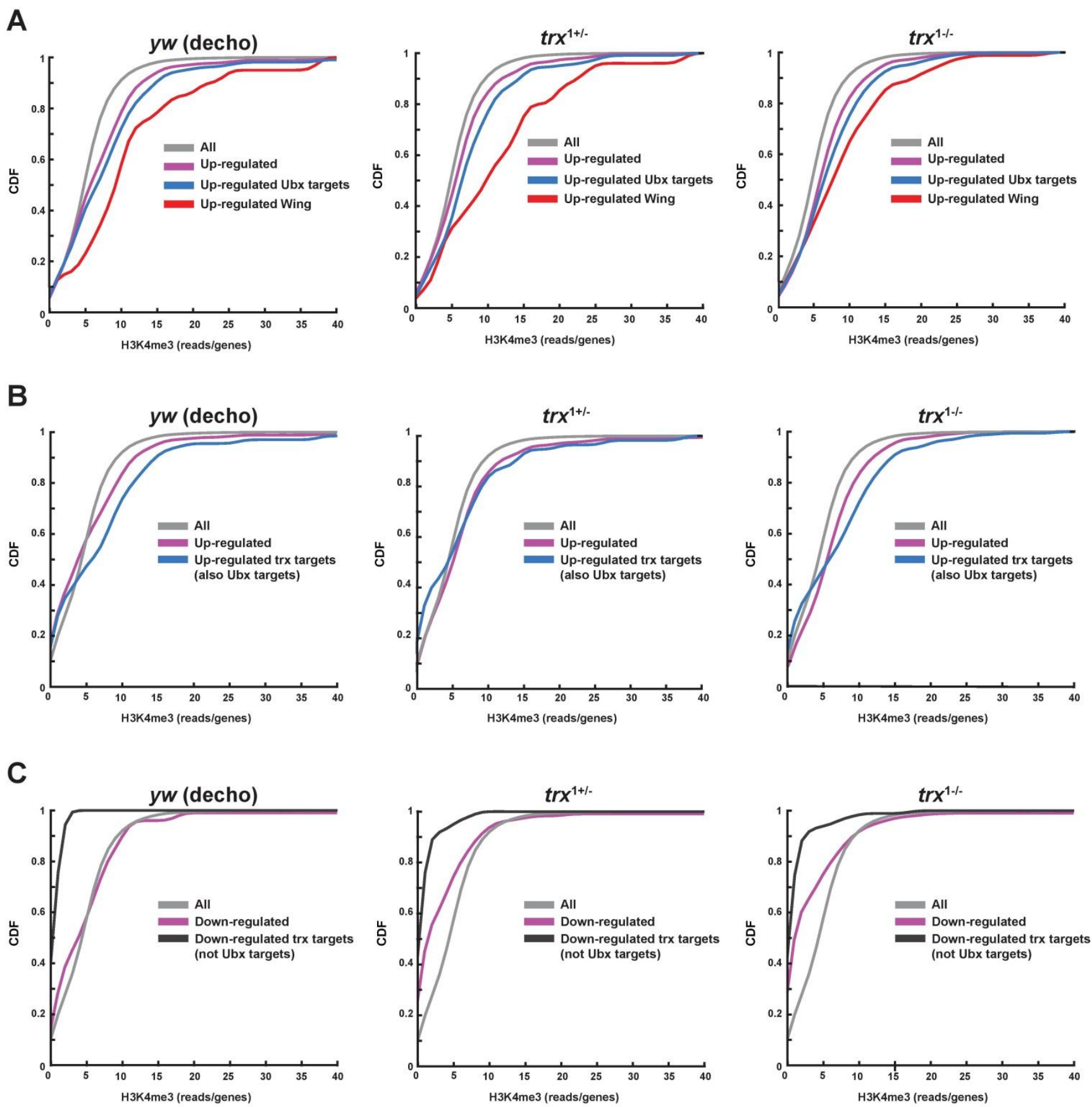

Fig. S4. Up-regulation of wing genes in the haltere correlates with high $\mathrm{H} 3 \mathrm{~K} 4 \mathrm{me} 3$ at the time of exposure. Related to Figure 4.(A) Cumulative distributions (CDFs) of H3K4me3 levels shortly after ether exposure, shown for all genes with detectable H3K4me3 (grey), genes that are significantly up-regulated in the haltere disc (pink), up-regulated wing development genes and up-regulated Ubx targets (red and blue, respectively). Up-regulated gene sets in each panel are based on expression measurements in dechorionated $y w$ flies (left), $t r x^{1+-}$ flies (center) and $t r x^{-1 /-}$ (right). CDFs are based on the sum of normalized H3K4me3 reads for each gene. (B) Same as (A) with replacement of the last two groups with up-regulated genes that are joint targets of trx and Ubx (blue). (C) Same as (B) with replacement of the last two groups with significantly down-regulated genes in the haltere disc (pink) and down-regulated genes that are joint targets of trx and Ubx (black). 


\begin{tabular}{|c|c|c|}
\hline Group 1 & Group 2 & Adjusted $p$-value \\
\hline (+)Ether:(+)Decho & $(-)$ Ether:(+)Decho & $2.84 \mathrm{E}-05$ \\
\hline (-)Ether:(-)Decho & $(-)$ Ether:(+)Decho & 0.988639 \\
\hline$(+)$ Ether:(-)Decho & $(-)$ Ether:(+)Decho & 0.239086 \\
\hline$(-)$ Ether:(-)Decho & $(+)$ Ether:(+)Decho & 0.000008 \\
\hline$(+)$ Ether:(-)Decho & $(+)$ Ether:(+)Decho & 0.013533 \\
\hline$(+)$ Ether:(-)Decho & $(-)$ Ether:(-)Decho & 0.12645 \\
\hline
\end{tabular}

Table S1. Post-hoc analysis p-values of the pairwise comparisons between survival rates under egg dechorionation and ether treatment. Related to Figure 1. The analysis was carried on the number of pupae developed from eggs with or without dechorionation ('Decho') and with or without ether treatment ('Ether'). Each row represents a Tukey HSD analysis performed on a specific pair of the conditions above. 


\begin{tabular}{|l|l|c|}
\hline \multicolumn{1}{|c|}{ Group 1 } & \multicolumn{1}{|c|}{ Group 2 } & Adjusted $p$-value \\
\hline Uneclosed pupae:(+)Decho & Adults:(+)Decho & 0.8945915 \\
\hline Adults:(-)Decho & Adults:(+)Decho & 0.0000002 \\
\hline Uneclosed pupae:(-)Decho & Adults:(+)Decho & 0.0000011 \\
\hline Adults:(-)Decho & Uneclosed pupae:(+)Decho & 0 \\
\hline Uneclosed pupae:(-)Decho & Uneclosed pupae:(+)Decho & 0 \\
\hline Uneclosed pupae:(-)Decho & Adults:(-)Decho & 0.984468 \\
\hline
\end{tabular}

Table S2. Post-hoc p-values of the pairwise comparisons between bithorax penetrance rates in uneclosed pupae and adult flies after egg dechorionation. Related to Figure 1.

The analysis was carried on the fraction of phenocopied uneclosed pupae or adult flies developed from eggs with or without dechorionation ('Decho') after ether treatment. Each row represents a Tukey HSD analysis performed on a specific pair of the conditions and developmental stages above. 


\begin{tabular}{|c|c|}
\hline Gene network & Adjusted p-value \\
\hline Spliceosome & $8.58 \mathrm{E}-32$ \\
\hline Ribosome & $2.81 \mathrm{E}-31$ \\
\hline Hippo signaling pathway - fly & $1.35 \mathrm{E}-28$ \\
\hline RNA degradation & $2.96 \mathrm{E}-24$ \\
\hline Ubiquitin mediated proteolysis & $9.23 \mathrm{E}-24$ \\
\hline Endocytosis & $5.66 \mathrm{E}-23$ \\
\hline RNA transport & $2.96 \mathrm{E}-20$ \\
\hline FoxO signaling pathway & $2.96 \mathrm{E}-20$ \\
\hline Wnt signaling pathway & $3.09 \mathrm{E}-19$ \\
\hline Protein processing in endoplasmic reticulum & $2.80 \mathrm{E}-15$ \\
\hline mRNA surveillance pathway & $1.31 \mathrm{E}-14$ \\
\hline Hedgehog signaling pathway & $6.61 \mathrm{E}-14$ \\
\hline TGF-beta signaling pathway & $1.04 \mathrm{E}-11$ \\
\hline mTOR signaling pathway & $2.12 \mathrm{E}-11$ \\
\hline Jak-STAT signaling pathway & $1.87 \mathrm{E}-08$ \\
\hline Notch signaling pathway & 4.31E-08 \\
\hline Phagosome & 0.00348 \\
\hline Regulation of autophagy & 0.0365 \\
\hline
\end{tabular}

Table S3. Gene network enrichment analysis of the genes with promoter regions within the highest H3K4me3 retention levels (top 10\%). Related to Figure 2. 


\begin{tabular}{|c|c|c|}
\hline Group 1 & Group 2 & Adjusted p-value \\
\hline $\operatorname{tr} x^{1--}:(-)$ Ether & $\operatorname{tr} x^{l+/-}:(-)$ Ether & 0 \\
\hline$y w:(-)$ Ether & $\operatorname{tr} x^{l+/-}:(-)$ Ether & 1 \\
\hline$y w$ Decho:(-)Ether & $\operatorname{tr} x^{l+-}:(-)$ Ether & 1 \\
\hline $\operatorname{tr} x^{l+/-}:(-)$ Ether & $\operatorname{tr} x^{l+/}:(+)$ Ether & 0 \\
\hline $\operatorname{tr} x^{1-/-}:(+)$ Ether & $\operatorname{tr} x^{l+-}:(-)$ Ether & 0 \\
\hline$y w:(+)$ Ether & $\operatorname{tr} x^{l+/}:(-)$ Ether & 0.0000004 \\
\hline$y w$ Decho:(+)Ether & $\operatorname{tr} x^{I+-}:(-)$ Ether & 0 \\
\hline$y w:(-)$ Ether & trx $x^{I---}:(-)$ Ether & 0 \\
\hline$y w$ Decho:(-)Ether & trx $x^{1---}:(-)$ Ether & 0 \\
\hline $\operatorname{tr} x^{I+/}:(+)$ Ether & trx $x^{I--}:(-)$ Ether & 0.048322 \\
\hline $\operatorname{tr} x^{1-/-}:(+)$ Ether & trx $x^{I--}:(-)$ Ether & 0 \\
\hline$y w:(+)$ Ether & $\operatorname{tr} x^{1---}:(-)$ Ether & 0.0057505 \\
\hline$y w$ Decho: $(+)$ Ether & $\operatorname{tr} x^{I-/-}:(-)$ Ether & 0.6117278 \\
\hline$y w$ Decho:(-)Ether & $y w:(-)$ Ether & 1 \\
\hline $\operatorname{tr} x^{l+/}:(+)$ Ether & $y w:(-)$ Ether & 0 \\
\hline $\operatorname{tr} x^{1-1}:(+)$ Ether & $y w:(-)$ Ether & 0 \\
\hline$y w:(+)$ Ether & $y w:(-)$ Ether & 0.0000004 \\
\hline$y w$ Decho:(+)Ether & $y w:(-)$ Ether & 0 \\
\hline $\operatorname{tr} x^{l+/-}:(+)$ Ether & $y w$ Decho:(-)Ether & 0 \\
\hline $\operatorname{tr} x^{1-1}:(+)$ Ether & $y w$ Decho:(-)Ether & 0 \\
\hline$y w:(+)$ Ether & $y w$ Decho:(-)Ether & 0.0000004 \\
\hline$y w$ Decho:(+)Ether & $y w$ Decho:(-)Ether & 0 \\
\hline $\operatorname{tr} x^{l-/-}:(+)$ Ether & $\operatorname{tr} x^{l+/}:(+)$ Ether & 0.000002 \\
\hline$y w:(+)$ Ether & $\operatorname{tr} x^{l+/}:(+)$ Ether & 0 \\
\hline$y w$ Decho:(+)Ether & $\operatorname{tr} x^{l+/}:(+)$ Ether & 0.0000479 \\
\hline$y w:(+)$ Ether & $\operatorname{tr} x^{1-/}:(+)$ Ether & 0 \\
\hline$y w$ Decho:(+)Ether & $\operatorname{tr} x^{l-\digamma}:(+)$ Ether & 0 \\
\hline$y w$ Decho:(+)Ether & $y w:(+)$ Ether & 0.0418766 \\
\hline
\end{tabular}

Table S4. Post-hoc p-values of the pairwise comparisons between penetrance rates under different genotypes and ether treatment. Related to Figure 2.

The analysis was carried on the fraction of pupae and adult flies presenting the bithorax phenocopy out of the total number per bottle. The different backgrounds ( $y w, y w$ Decho, $\operatorname{tr} x^{1+-}$ and $\operatorname{tr} x^{1--}$ ) were either developed from eggs exposed to ether treatment ('Ether') or not. Each row represents a Tukey HSD analysis performed on a specific pair of the conditions above. 


\begin{tabular}{|c|l|c|}
\hline \multirow{2}{*}{ Set of genes } & \multicolumn{1}{|c|}{ Factor } & p-value \\
\hline \multirow{2}{*}{ Ubx targets } & Genotype & $2.00 \mathrm{E}-16$ \\
\cline { 2 - 3 } & Ether & $2.68 \mathrm{E}-11$ \\
\cline { 2 - 3 } & Genotype:Ether & $7.79 \mathrm{E}-07$ \\
\hline \multirow{4}{*}{$\begin{array}{c}\text { trx targets (also Ubx } \\
\text { targets) }\end{array}$} & Genotype & $6.34 \mathrm{E}-15$ \\
\cline { 2 - 3 } & Ether & $1.08 \mathrm{E}-11$ \\
\cline { 2 - 3 } & Genotype:Ether & $9.95 \mathrm{E}-05$ \\
\hline \multirow{2}{*}{$\begin{array}{c}\text { trx targets (not Ubx } \\
\text { targets) }\end{array}$} & Ether & $2.28 \mathrm{E}-08$ \\
\cline { 2 - 3 } & Genotype:Ether & $3.64 \mathrm{E}-05$ \\
\cline { 2 - 3 } & & $1.33 \mathrm{E}-08$ \\
\hline
\end{tabular}

Table S5: ANOVA p-values of the analysis of mean expression level of relevant subsets of trx and Ubx targets. Related to Figure 3. 


\begin{tabular}{|c|c|c|}
\hline Set of genes & Factor & p-value \\
\hline \multirow{3}{*}{ Wing-related genes } & Genotype & $8.91 \mathrm{E}-16$ \\
\hline & Ether & $1.51 \mathrm{E}-09$ \\
\hline & Genotype:Ether & $8.51 \mathrm{E}-07$ \\
\hline \multirow{3}{*}{$\begin{array}{l}\text { Wing-related genes } \\
\text { (also Ubx targets) }\end{array}$} & Genotype & $8.62 \mathrm{E}-16$ \\
\hline & Ether & $1.28 \mathrm{E}-09$ \\
\hline & Genotype:Ether & $1.57 \mathrm{E}-06$ \\
\hline
\end{tabular}

Table S6: ANOVA p-values of the analysis of mean expression level of relevant subsets of wing-related genes. Related to Figure 3. 
Data S1. Embryo FPKM (separate excel file)

FPKM values in ether-exposed and non-exposed $y w, y w$ decho, $t r x^{1+/}$ and $t r x^{1-/-}$ embryos.

\section{Data S2. Haltere FPKM (separate excel file)}

FPKM values in ether-exposed and non-exposed $y w, y w$ decho, $t r x^{1+/}$ and $t r x^{1-/-} 3^{\text {rd }}$ larvae haltere imaginal discs. 
bioRxiv preprint doi: https://doi.org/10.1101/482216; this version posted November 29, 2018. The copyright holder for this preprint (which was not certified by peer review) is the author/funder. All rights reserved. No reuse allowed without permission. 